\title{
TRANSPARENCIA Y BUEN GOBIERNO. EL VALEDOR DO POBO EN LA LUCHA CONTRA LA CORRUPCIÓN POLÍTICA*
}

\author{
Ma Begoña López Portas**
}

Resumen: La Ley 1/2016 integra en una única norma toda la regulación referida a la rendición de cuentas de los poderes públicos gallegos. El Valedor do Pobo se convierte en protagonista en su interpretación y aplicación. Unas nuevas funciones de la institución que requieren un análisis crítico desde el punto de vista de la lucha contra la corrupción política.

Palabras clave: Corrupción pública, Defensor del Pueblo, Valedor do Pobo, principio de transparencia y derecho a la buena administración.

\section{Recibido: junio 2017. Aceptado: septiembre 2018}

* Este trabajo se enmarca dentro de las labores de investigación realizadas al amparo del Proyecto de investigación DER2015-71176-R, "Nuevos instrumentos jurídicos en la lucha contra la corrupción pública: propuestas desde el derecho penal y el derecho constitucional" financiado por el Ministerio de Economía y Competitividad y cofinanciado por el Fondo Europeo de Desarrollo Regional (FEDER) correspondiente al marco financiero plurianual 2014-2020.

** Profesora Contratado Doctor de Derecho Constitucional. ORCID ID: 00000003-3556-0422

Departamento de Derecho Público y Teoría del Estado. Facultad de Derecho de la Universidad de Santiago de Compostela. Avda. Ángel Echeverri, S/N. Campus Vida, CP. 15785, Santiago de Compostela. Email: begonha.lopez. portas@usc.es 
TRANSPARENCY AND GOOD GOVERNANCE.

THE VALEDOR DO POBO IN THE FIGHT AGAINST

THE PUBLIC CORRUPTION

Abstract: All the regulation about the accountability of the public authorities of Galicia is integrated in the 1/2016 law. The Valedor do Pobo becomes in a principal actor in its interpretation and application. Due to this, institution's new functions require a critical analysis of the point of view of the fight against political corruption.

Keywords: Public Corruption, Ombusdman, Valedor do Pobo, Principle of Transparency and right to good administration.

\section{Introducción: Breves consideraciones sobre la figura del Defensor del Pueblo y su necesaria configuración como un sistema de protección de los ciudadanos en la lucha contra la corrupción pública}

En la actualidad, la corrupción política se ha extendido hasta el punto que conforma un nuevo elemento que define nuestro modelo de gobierno. De modo que puede entenderse como una patología política general a la que debe hacerse frente no sólo en la medida en que vicia la adopción de decisiones por los órganos del Estado y por el alto coste que suscita en términos de confianza ciudadana si no porque redundan en una distorsión del Estado social y democrático de Derecho.

La legitimidad democrática de los gobernantes exige que éstos guarden respeto cualificado a ciertas normas de conducta tanto jurídicas como políticas que pueden concretarse en textos de naturaleza cuasi constitucional - como son las leyes de incompatibilidades de los altos cargos o las normas de transparencia y buen gobierno- - Con el fin de hacer frente a los supuestos de corrupción política que puedan producirse, el proceso de rendición de cuentas actúa de una forma tanto represiva - que, en caso del quebrantamiento de normas jurídicas, puede conllevar una sanción penal, en el supuesto de incurrir en ilícitos penales ${ }^{1}$

1 En todo caso, no podemos obviar que la lucha contra la corrupción pública exige no sólo que cada Estado implemente soluciones ajustadas a su 
como también de una manera preventiva - mediante la adopción de una serie de medidas que pueden tener un efecto disuasorio-

La principal característica que presentan los trabajos que han abordado la cuestión de la corrupción política es su interdisciplinariedad. Un rasgo de heterogeneidad que, como apunta BUSTOS GISBERT, condiciona su estudio jurídico-constitucional y plantea la necesidad de perfilar una definición útil para los juristas ${ }^{2}$. La proliferación de estudios que abordan el tema desde perspectivas diferentes, aunque permiten su comprensión desde una pluralidad de puntos de vista, sin embargo, al mismo tiempo condicionan la perspectiva de análisis ya que el concepto utilizado en las distintas disciplinas hace imposible reconocer un idéntico objeto de investigación salvo que se entiendan de modo complementario. Por este motivo, surge la necesidad de establecer una definición jurídica de corrupción política útil antes de adentrarnos en la novedosa configuración que experimenta la figura Valedor do Pobo como instrumento político de transparencia y buen gobierno a partir de la Ley gallega 1/2016. Sólo así podremos comprender la eficacia de las medidas normativas adoptadas en este sentido.

realidad normativa, económica y sociológica, si no que es necesario el establecimiento de unas estrategias y marcos de actuación comunes con el fin de evitar políticas anticorrupción asimétricas que distorsionen el funcionamiento del mercado y el crecimiento económico. (Cfr., VÁZQUEZ PORTOMEÑE SEIJAS, Fernando: “Corrupción política y globalización. Una mirada a la regulación del tráfico de influencias en los instrumentos internacionales anti-corrupción", en Revista Dereito: Revista xurídica da Facultade de Dereito, vol. 26, nº 1 , enero-junio, USC, 2017, pp.2 y 3; (http:// dx.doi.org/10.15304/dereito.26.1.3727, página web consultada 1/9/2017 a las 09.00h).

2 En este sentido, BUSTOS GISBERT apunta el estudio de la corrupción política presenta como dificultad esencial una conceptualización del término heterogénea si bien desde ramas del conocimiento metodológicamente muy dispares se aportan diferentes formas de aproximación son, en diferente medida, complementarias entre sí por lo que confieren ideas o reflexiones de plena utilidad para el citado análisis jurídico constitucional ( $C f r$. BUSTOS GISBERT, Rafael: "Corrupción política: Un análisis desde la Teoría Jurídico-Constitucional”, Revista Teoría y Realidad Constitucional, n²5, UNED, Madrid, 2010, pp.73-74). 
Así pues, con carácter general entenderemos que la corrupción política puede ser definida como la traición - normalmente mantenida en secreto- de la confianza popular otorgada de forma directa o indirecta a los gobernantes mediante la ruptura de las reglas reguladoras de esa relación debido al interés de obtener un beneficio otorgado por un tercero. Esas reglas reguladoras vulneradas incluyen un conjunto heterogéneo de normas - jurídicas y éticas - que requieren ser protegidas tanto desde un punto de vista jurídico como desde un punto de vista político ${ }^{3}$. El control penal de la corrupción política actúa como un control de última instancia, para las degradaciones criminales de la política en el ámbito administrativo en atención al principio de legalidad o incompatibilidades. En cambio, las medidas extrapenales de lucha contra la corrupción se extienden sobre el ámbito constitucional bajo la necesidad de preservar la transparencia, buen gobierno, y la determinación de distintos regímenes de incompatibilidades de las autoridades gubernativas o de los funcionarios. Bajo este parámetro surge la necesidad de supervisar la actividad administrativa con el fin de garantizar su correcto funcionamiento.

La proclamación del Estado español como un estado social y democrático de Derecho contenido en el primero de los artículos de la Constitución española conlleva no sólo a la protección y garantía de los los derechos fundamentales sino que incluye el control de la actividad de la Administración a través de distintos medios como son el control administrativo interno —basado en el principio jerárquico-, el control parlamentario y el control jurisdiccional. El carácter interno del primero de ellos, las características políticas propias del segundo, y la particularidad de la costosidad en tiempo y dinero de las terceras, plantean la necesidad de una institución más ágil y flexible que complete las posibilidades de protección de las que dispone el

3 Cfr., BUSTOS GISBERT, Rafael: “Corrupción política: Un análisis desde la Teoría Jurídico-Constitucional”, Revista Teoría y Realidad Constitucional, n²5, UNED, Madrid, 2010, p.103. 
ciudadano frente a las actividades del poder ${ }^{4}$. En consecuencia, el artículo 54 de la Carta Magna crea la figura del Defensor del Pueblo como Alto Comisionado de las Cortes generales para la defensa de los derechos proclamados en su Título $\mathrm{I}^{5}$ y como supervisor de la actividad de la Administración. El Defensor del Pueblo informa de su labor a las Cortes y, como intermediario, le traslada la opinión de los ciudadanos sobre las deficiencias apreciadas respecto a la actuación administrativa. Los contornos que perfilan al Defensor del Pueblo están constituidos por una serie de notas características que la definen como una institución sui generis.

Por un lado, nos encontramos ante una figura que desarrolla labores de supervisión que corresponderían a otras instancias específicas, en este ámbito se integrarían su labor de control jurisdiccional que corresponde a la jurisdicción contencioso-administrativa y su función de promoción de la acción de la justicia en defensa de la legalidad y de los derechos de los ciudadanos desarrollada también por el Ministerio Fiscal. Nos hallamos ante un órgano auxiliar de las Cortes si bien las dos actividades que se le encomiendan — la de supervisión la actividad administrativa y la de interposición de los recursos de inconstitucionalidad y de amparo ante el Tribunal Constitucional- constituyen, en todo caso, su función de control que parece contradictoria al ser considerado Alto comisionado de las Cortes generales, pero que, sin embargo, es una competencia que en buena medida viene determinada por su naturaleza y funciones enfocada en la de-

4 Cfr., VERA SANTOS, J. M.: El Defensor del Pueblo en la Constitución y en los Estatutos de autonomía, colección textos y documentos, $\mathrm{n}^{\circ} 13$, Centro de Estudios Político Constitucionales, BOE, Madrid, 2002, pp.17 y 18.

5 Recordemos que nos encontramos ante una garantía sui generis de los derechos fundamentales y deberes fundamentales recogidos con distinto grado de efectividad en el Título I de la Constitución. Motivo por el que esta institución es categorizada por la doctrina como garantía institucional - BALAGUER CALLEJÓN-, extrajudicial —ÁLVAREZ CONDE-, o como garantía orgánica, al suponer la creación de órgano específico —PÉREZ ROYO-. 
fensa de los derechos señalados ${ }^{6}$. En este sentido debe añadirse que PÉREZ ROYO subraya que la apariencia ilógica de su facultad más importante - la posibilidad de interponer recurso de inconstitucionalidad frente a los actos de las Cortes Generalespuede entenderse desde la óptica de la carencia de legitimación de los ciudadanos. De tal manera que, el Alto Comisionado de las Cortes para supervisar la actividad de la Administración puede impugnar los actos de legislativo y canalizar por esta vía las peticiones de la ciudadanía?

Por otro lado, cabe destacar que otra de las particularidades que presenta el Defensor del Pueblo y lo identifican respecto a otras instituciones análogas del derecho comparado o del derecho autonómico es su peculiar posición jurídico constitucional al estar legitimado para interponer no sólo el recurso de amparo sino también el recurso de inconstitucionalidad. Dos paradigmáticas funciones no creadoras de derecho y, en consecuencia, no constitucionales, no activas ${ }^{8}$ que no están exentas de críticas doctrinales en términos de utilidad de la institución y contrariedad funcional. Hasta el punto que autores como TORRES MURO definen como inapropiado su diseño constitucional, al entender que la escasa influencia que ha tenido el Defensor en la interposición de recursos de inconstitucional ha supuesto más problemas que soluciones a nuestro régimen constitucional y no ha permitido que centrase su actuación en su función de control de la actividad administrativa lo que lo ha devaluado como defensor de los derechos fundamentales por lo que se plantea

6 Cfr., AGUIAR de LUQUE, L.: "Defensor del Pueblo", en AA.VV. Derechos fundamentales y su protección. Temas básicos de Derecho Constitucional. Tomo III, M. ARAGÓN REYES (dir.), Civitas Thonsom-Reuters, editorial Aranzadi, Cizur Menor, 2011, p. 127.

7 Cfr., PÉREZ ROYO, J.: Curso de Derecho Constitucional, (Decimocuarta edición), Marcial Pons, Madrid, 2014, p.474.

8 Cfr., VARELA SUANZES-CARPEGNA, J.: "Naturaleza jurídica del Defensor del Pueblo", Revista Española de Derecho Constitucional, Año 3, $\mathrm{n}^{\circ} 8$, mayo-agosto, 1983, p. 64 (. https://dialnet.unirioja.es/descarga/articulo/249714.pdf, página web consultada 27/06/2017 a las 14.56 horas). 
como necesario un futuro desarrollo del Estado constitucional que potencie esta función ${ }^{9}$. En esta misma línea, COLOMER VIADEL plantea la necesidad de una revisión a fondo de la organización y funcionamiento de la institución del Defensor del Pueblo, a partir de sus regulaciones constitucionales, legales y reglamentarias, para lograr su fortalecimiento institucional e incluso plantea como vía jurídica la reforma constitucional ${ }^{10}$.

Finalmente, aunque nos encontramos ante una figura constitucionalizada que mantiene una relación de auxilio con las Cortes, esta relación es autónoma tanto desde el punto de vista orgánico como funcional. La Constitución y la Ley orgánica del Defensor del Pueblo establecen un nexo entre el Defensor del Pueblo y las Cortes Generales, que, han perseguido obtener un efecto tanto de carácter positivo - la vinculación de este órgano al Parlamento - como de carácter negativo — su total desvinculación respecto del ejecutivo-. Esa particular posición jurídico constitucional exige garantizar su autonomía e independencia respecto a las Cortes y al mismo tiempo va a permitir el desarrollo de una importante función de control de la Adminis-

9 Cfr., TORRES MURO, I.: "Los recursos del Defensor del Pueblo ante el Tribunal Constitucional. Una revisión”, en la Revista Teoría y Realidad Constitucional, n²6, UNED, Madrid, 2010, p.124.

10 Para potenciar la institución el Profesor COLOMER VIADEL enumera como necesarias las siguientes reformas: incrementar la actividad del Gabinete de Prensa y Medios del Defensor y la publicación en tales medios de los nombres de los responsables últimos de la mala administración; reforzar el carácter unipersonal del Defensor del Pueblo; mayor severidad en la aplicación de las medidas legales de actuación del Defensor; reformar la Ley orgánica del Defensor del Pueblo bajo su propuesta para perfilar su figura, y atribuciones, ordenar y coordinar las normas, diseñar un sistema que permita el incremento de la operatividad del Defensor en la aplicación del Derecho comparado, potenciar legalmente sus aspectos positivos, la ampliación de la institución del Defensor al ámbito municipal, coordinado con los comisionados autonómicos; etc ( $C f r$ r. COLOMER VIADEL, A.: "El Defensor del Pueblo: un órgano políticoadministrativo de protección de los derechos", Revista de Derecho Político, $\mathrm{n}^{\circ} 70-71$, enero-agosto, UNED, Madrid, 2008, pp.72-73 (http://e-spacio.uned.es/fez/eserv.php?pid=bibliuned:DerechoPoli tico2008-2\&dsID=PDF página web consultada 25/09/2017 a las $16.54 \mathrm{~h}$ ). 
tración Pública que la configuran como un complemento necesario al principio de Transparencia y Buen Gobierno.

De esta manera, observamos que el Defensor del Pueblo se ha configurado jurídicamente como una pieza clave a la hora de supervisar la actuación de las administraciones públicas aunque presenta ciertas peculiaridades y que no le eximen de críticas. A partir de ahí, cabe plantearse si, por extensión, las defensorías del pueblo pueden ser un instrumento efectivo de control de la actividad administrativa. Por este motivo surge la necesidad de valorar la articulación de esta figura como un instrumento válido de lucha contra las irregularidades que puedan producirse en el ejercicio de la acción de las Administraciones Públicas. A lo largo de estas líneas nos centraremos en el análisis de su función de supervisión en la medida que nos sirva de mecanismo control y, último término, de contención y de erradicación de la corrupción política como plantea la Ley gallega 1/2016 en relación con la figura del Valedor do Pobo.

\section{La supervisión de las Administraciones públicas por las defensorías del Pueblo: Particularidades de indefinición y nuevos retos}

Como subrayamos, el Defensor del Pueblo puede convertirse en un mecanismo eficaz en la lucha contra la corrupción política al tener encomendada la facultad de control de la actuación de las administraciones públicas. Una labor de extrema importancia que requiere ser perfilada para que podamos entender en qué medida puede configurarse como un instrumento fiscalizador y disuasorio de los actos de corrupción. En este apartado nos detendremos en subrayar cuáles son los principales problemas que condicionan su eficacia a la hora de ejercer esta función y a los que deben hacer frente las defensorías del pueblo en la defensa de los derechos y principios rectores de los ciudadanos mediante el control de las administraciones públicas. Al respecto, debemos comenzar indicando cuáles son los parámetros que defienden su ámbito competencial y a partir de ahí determinar 
cuáles son los retos que se presentan de cara a su actuación eficiente y eficaz.

A tenor de los artículos 1 y 9.1 de la Ley orgánica del Defensor del Pueblo, el alto Comisionado de las Cortes Generales, entre sus competencias, tiene encomendada la facultad de supervisar la actividad de la Administración en atención al artículo 103 y del Título I de la Constitución. Las funciones fiscalizadoras del Defensor del Pueblo sobre la Administración Pública son amplias conforme al artículo 9.2 de la Ley orgánica del Defensor del Pueblo y, de acuerdo con el artículo 12.1, se extienden a la supervisión de la actividad de las Comunidades autónomas en el ámbito competencial, incluida la Administración Militar, descrito en su Ley orgánica. El examen de la legalidad en la actuación administrativa se comprende en un sentido extenso ya que las previsiones contenidas en esta norma - en concreto, los artículos 23 y 25.1 - permiten la posibilidad de supervisar el comportamiento de las autoridades y funcionarios que den lugar a la queja planteada pudiendo dar cuenta al superior jerárquico del funcionario implicado o al Fiscal General del Estado si la conducta fuese presumiblemente delictiva. En todo caso, el Defensor del Pueblo puede de oficio ejercer la acción de responsabilidad contra todas las autoridades, funcionarios y agentes civiles del orden gubernativo o administrativo, incluso local, sin necesidad de previa reclamación por escrito.

Debe subrayarse que, sin embargo, el Defensor del Pueblo no puede inmiscuirse en asuntos judiciales, si no que su función es la de supervisión de la actividad de la Administración. Ahora bien, debemos recordar que el artículo 106.1 de la Constitución encomienda el control de la legalidad de la actuación administrativa a los Tribunales de la Jurisdicción contencioso administrativa. Por este motivo, la acción del Defensor del Pueblo en este ámbito se limita a determinados supuestos, como subraya GARRIDO FALLA ${ }^{11}$ y plantea serios problemas de indeterminación material como veremos más adelante.

11 GARRIDO FALLA enumera tres supuestos en los que puede plantearse la actuación de supervisión del Defensor del Pueblo sobre la actividad admi- 
En el ejercicio de esta actividad de supervisión el Defensor del Pueblo puede iniciar de oficio o a instancia de parte cualquier investigación conducente al esclarecimiento de actos y resoluciones no sólo de la Administración pública si no también de sus agentes. A partir de ahí, se advierte un primer problema a la hora de delimitar esta función: la indeterminación del sujeto pasivo susceptible del control del Defensor del Pueblo. De manera que, sus competencias de supervisión puede comprenderse que se extienden no sólo sobre la Administración en sentido orgánico si no que alcanza también el ejercicio de competencias públicas por personas jurídico-privadas constituidas o no por la Administración Pública ${ }^{12}$. Una falta de delimitación clara que se ve desbordada por el hecho de que en muchas de las leyes autonómicas se aprecia una voluntad expansiva de competencias de control de las figuras análogas en las comunidades autónomas. Así, en este sentido se incluyen como sujetos sometidos a su labor de fiscalización también a los organismos autónomos, empresas y sociedades públicas, concesionarios y fundaciones

nistrativa ya controlada por la Jurisdicción contencioso administrativa. En primer lugar, en el caso de que un particular haya formulado sus reclamaciones vía administrativa y esta no se resuelva, entonces el asunto puede plantearse ante el Defensor del Pueblo sin que la Administración pueda alegar que transcurriesen los plazos para recurrir por silencio administrativo y que la desestimación hubiera ganado firmeza. En segundo término, cuando el particular haya acudido ante la Jurisdicción Contencioso Administrativa, la Administración no puede impedir la actuación del Defensor alegando que la cuestión está sub judice, ya que la Ley de la Jurisdicción Contencioso Administrativa, permite que, interpuesto el recurso, la Administración reconozca en vía administrativa la pretensión del demandante, pudiendo mediar aquí el Defensor del Pueblo. Y, en tercer lugar, si la Jurisdicción Contencioso Administrativa dictó una sentencia absolutoria para la Administración, el Defensor ha de respetarla si bien puede sugerir modificaciones legislativas (Cfr., GARRIDO FALLA, R.: "Artículo 54", en AA.VV.: Comentarios a la Constitución, Tercera edición ampliada, R. GARRIDO FALLA (coord.), Civitas Ediciones SL., Madrid, 2001, p.994).

$12 C f r$, IGLESIAS GONZÁLEZ, F.: “Artículo 28”, en AA.VV.: Comentarios a la Ley orgánica del Defensor del Pueblo, Antonio ROVIRA VIÑAS (dir.), colección Monografías Aranzadi, $n^{\circ}$ 231, Defensor del Pueblo y Thomson, editorial Aranzadi, Cizur Menor, 2002, p.700. 
dependientes de las distintas administraciones autonómicas. Este es el caso de la Comunidad autónoma gallega, a la que de forma específica nos referiremos en el último de los apartados de este trabajo. Aunque el artículo 13 de la Ley 6/1984, de 5 de junio, del Valedor do Pobo, reproduce el contenido del artículo 9.1 de la norma estatal; sin embargo, la Ley gallega va más allá al ampliar su ámbito subjetivo. Por un lado, con carácter previo, el artículo artículo 1.3 de la Ley 6/1984, de 5 junio, extiende esta labor de supervisión tanto sobre la actividad de la Administración gallega como sobre sus entes y empresas públicas o dependientes. Por otro lado, el artículo 13.2 determina que la actividad llevada acabo por los Conselleiros y cualesquiera autoridades administrativas, funcionarios y agentes que actúen al servicio de la Administración de la Comunidad Autónoma y a sus Entes o Empresas dependientes está supeditada al control del Valedor.

A esta indeterminación subjetiva debe añadirse un segundo problema, la indefinición del ámbito material susceptible de control. El concepto de actividad de naturaleza administrativa susceptible de control puede plantear algunas dificultades cuando las leyes reguladoras de la institución no atribuyen expresamente la facultad de fiscalizar la actividad administrativa del legislativo autonómico - en concreto nos referimos a cuestiones como pueden ser las quejas respecto al desarrollo de procedimientos selectivos de personal convocados por el Parlamento autonómico o ante la gestión de su patrimonio-, por lo que se plantea la necesidad de determinar si le corresponde al Defensor la supervisión de la actividad administrativa parlamentaria. Al respecto, GARCÍA ÁLVAREZ entiende que la inexistencia de una habilitación legal expresa no puede condicionar su ámbito competencial si no que la naturaleza garantizadora de derechos que reviste la Institución debe considerarse lo suficientemente fuerte como para suplir la atribución explícita de estas facultades ${ }^{13}$. En todo

13 Cfr., GARCÍA ÁlVAREZ, M. en AA.VV: "Encuesta sobre el Defensor del Pueblo", en la Revista Teoría y Realidad Constitucional, n²6, UNED, Madrid, 2010, pp. 45-46. 
caso, la incorporación a la normativa de previsiones específicas relativas al control del Defensor sobre la actividad administrativa legislativo puede ser más clarificadora en este punto simplemente habrá que confiar en la interpretación que pueda realizarse sobre el artículo 1 de la Ley reguladora de la Jurisdicción Contencioso Administrativa $^{14}$.

De este modo, observamos que la delimitación del ámbito competencial de esta figura respecto a otros órganos o instituciones de gobierno se convierte en un elemento esencial a la hora de perfilar los contornos que definen a la institución pero al mismo tiempo no podemos obviar la necesidad de clarificar las facultades que corresponden la Defensor del Pueblo y a su homólogos autonómicos. Es decir, la delimitación de competencial debe proyectarse ad extra y ad intra. Mientras que la delimitación competencial ad extra se asienta sobre la eficacia del principio de independencia - al que ya nos hemos referido al comienzo de este trabajo-, la delimitación competencial ad intra se articula sobre los principios de colaboración, coordinación y cooperación entre Defensor del Pueblo y figuras análogas autonómicas ${ }^{15}$. Estos principios deben actuar al mismo tiempo sólo así puede garantizarse un control pleno, efectivo y eficaz de la actividad administrativa.

14 Recordemos que, dentro del concepto de actividad administrativa fiscalizable, el artículo 1.3.a) de la Ley 29/1998, de 13 de julio, Ley reguladora de la jurisdicción contencioso administrativa incluye a los actos y disposiciones en materia de personal, administración y gestión patrimonial de los órganos de gobierno de las Asambleas legislativas de las Comunidades Autónomas así como de las instituciones autonómicas análogas al Tribunal de Cuentas y al Defensor del Pueblo.

$15 \mathrm{Al}$ no establecerse una normativa específica que determine la imposición del principio de jerarquía, la distinta naturaleza de las defensorías — constitucional, en el caso del Defensor del Pueblo, y autodispositiva estatutaria o normativa, en el supuesto de las autonómicas-, no justifica una vertebración jerárquica de sus relaciones si no la existencia de cierta prominencia del Defensor del Pueblo. Los principios de colaboración, coordinación y cooperación no articulan el reparto de competencias entre las defensorías si no que disciplinan su funcionamiento. Ahora bien, como subraya 
Respecto a la delimitación competencial ad extra de la eficacia de su control debe subrayarse que opera de una manera diferente respecto al poder legislativo y en relación al poder ejecutivo. Así, como Alto Comisionado de las Cortes designado por éstas será responsable de su gestión sólo ante ellas, mediante informes ordinarios o extraordinarios. Existe una vinculación real entre las Cortes y el Defensor del Pueblo, tanto desde el punto de vista orgánico - manifestada en el momento del nombramiento del titular y de los adjuntos - como funcional — dada su responsabilidad respecto a la tutela de los derechos fundamentales y en relación con la supervisión de la Administración y que se manifiesta en la presentación de los informes su relación con la Comisión Mixta del Congreso y Senado de relaciones con el Defensor del Pueblo- ${ }^{16}$. Para preservar esta independencia la Ley del Defensor del Pueblo establece unas garantías de inviolabilidad e inamovilidad que son extendidas a las figuras análogas autonómicas en virtud de la Ley 36/1985, si bien el aforamiento se entiende referido a la sala correspondiente del Tribunal Superior de Justicia de la Comunidad autónoma correspondiente. Una aplicación análoga de privilegios que RAMÓN FERNÁNDEZ llega a cuestionar como inconstitucional dado que el reconocimiento de la garantía de inviolabilidad y de fuero especial requiere que, al menos, se produzca de forma expresa en el Estatuto de autonomía ${ }^{17}$.

FERNÁNDEZ RODRÍGUEZ el empleo de estos tres principios es confuso y poco riguroso desde un punto de vista técnico-jurídico lo que dificulta la articulación de sus relaciones y redunda en ciertas disfunciones de operatividad (Cfr., FERNÁNDEZ RODRÍGUEZ, J. J.: "Defensor del Pueblo y defensorías autonómicas: Reflexiones sobre sus relaciones y posición recíproca", Revista Teoría y Realidad Constitucional, n²6, UNED, Madrid, 2010, pp.261, 262,267-271).

16 Cfr., VERA SANTOS, J. M.: El Defensor del Pueblo en la Constitución y en los Estatutos de autonomía, colección textos y documentos, $\mathrm{n}^{\circ} 13$, Centro de Estudios Político Constitucionales, BOE, Madrid, 2002, pp. 32-35.

17 En atención a la doctrina sentada por el Tribunal Constitucional 36/1981 respecto sobre la necesidad de que el estatus jurídico privilegiado de los parlamentarios vascos esté definido en el Estatuto de autonomía, RAMÓN 
El poder de control del Defensor sobre el Ejecutivo es mayor al tratarse de un órgano independiente del Gobierno. Como hemos indicado, a tenor de lo dispuesto en los artículos 9.2 y 12.1 de la Ley orgánica del Defensor del Pueblo la facultad de supervisión sobre la Administración Pública puede comprenderse como amplia, sin embargo, al mismo tiempo puede definirse como limitada. Conforme al artículo 28.1 de su Ley orgánica, el Defensor del Pueblo no puede anular o modificar los actos de la Administraciones Públicas. Sus facultades se circunscriben únicamente a las de sugerir la modificación de los criterios utilizados para la producción de esos actos y resoluciones y a la formulación de advertencias, recomendaciones y recordatorios de sus deberes legales y a la propuesta de nuevas medidas ${ }^{18}$. Las autoridades y funcionarios de las Administraciones Públicas correspondientes a las que se dirigen estas acciones sólo están obligadas a responder por escrito al Defensor del

FERNÁNDEZ sostiene la necesidad de que la modificación del estatus jurídico personal introducida por una ley ordinaria, la Ley 36/1985, requiere ser recogido en un precepto estatutario específico por lo que considera como irregulares e incluso inconstitucionales las extensiones con carácter general que puedan producirse al margen de una Ley orgánica ( $C f r$. RAMÓN FERNÁNDEZ, T. en $A A . V V$ : "Encuesta sobre el Defensor del Pueblo", en la Revista Teoría y Realidad Constitucional, n²6, UNED, Madrid, 2010, p. 39).

18 El artículo 28 de la Ley orgánica del Defensor del Pueblo no se refiere a la existencia de un cumplimiento riguroso de la norma por parte de las Administraciones Públicas si no que lo que resulta relevante para que intervenga el Defensor del Pueblo es si el pretendido cumplimiento genera situaciones injustas o perjudiciales para los ciudadanos. Es decir, el canon para poder exigir una modificación normativa por el Defensor del Pueblo es muy amplio ya que su justificación valorativa se sustenta sobre dos expresiones susceptibles de una interpretación extensa: la injusticia y el perjuicio. De este modo, se admite una extensión de las atribuciones del Defensor del Pueblo aunque con carácter general se articulan a través de meras recomendaciones sobre la modificación de normas ( $C f r$., IGLESIAS GONZÁLEZ, F.: "Artículo 28”, en AA.VV.: Comentarios a la Ley orgánica del Defensor del Pueblo, Antonio ROVIRA VIÑAS (dir.), colección Monografías Aranzadi, $\mathrm{n}^{\circ}$ 231, Defensor del Pueblo y Thomson, editorial Aranzadi, Cizur Menor, 2002, p.698). 
Pueblo en un plazo máximo de un mes tal y como establece el artículo 30.1 de la Ley orgánica ${ }^{19}$. En el caso de los funcionarios, el Defensor debe investigar su actuación en relación con la queja presentada, pudiendo exigirles responsabilidades por la vía judicial o ante el organismo competente, como veremos. Debe añadirse que los informes ordinarios y extraordinarios presentados por el Defensor ante las Cortes son otro mecanismo de control de la actividad administrativa, en ellos sólo se precisa el número de quejas y el tipo así como las diferencias y recomendaciones admitidas por las Administraciones pero deben omitir cualquier dato personal que permitan la identificación de los afectados por la investigación.

Desde un punto de vista de la delimitación competencial ad intra, advertimos que la potestad de supervisión administrativa universal del Defensor del Pueblo - en el sentido de que la Constitución lo legitima para el control de la Administración estatal, de las administraciones autonómicas y de las locales-, provoca dos graves problemas: impide cerrar con coherencia sus capacidades de actuación, ya que sólo ha de informar a las Cortes y no a los Parlamentos autonómicos - lo cual puede resultar de extrema importancia en la supervisión de las administraciones autonómica y local- $\mathrm{y}$, al mismo tiempo, produce el solapamiento de sus actuaciones con los defensores autonómicos, que, en ocasiones, puede derivar en la emisión de resoluciones distintas. Para facilitar esa coordinación, y lograr una mayor eficacia de la acción institucional, el artículo 2 de Ley orgánica 36/1985, de 6 de noviembre establece que el ejercicio concurrente de las competencias del Defensor y los comisionados autonómicos

19 Aunque el artículo 30 de la Ley orgánica del Defensor del Pueblo no lo especifique, lo razonable es que la respuesta emitida por la unidad administrativa correspondiente no debe limitarse a un mero acuse de recibo sin no que debe manifestar de modo expreso si se acepta o rechaza la recomendación recibida (Cfr., LÓPEZ GONZÁLEZ, J.L.: “Artículo 30”, en AA.VV.: Comentarios a la Ley orgánica del Defensor del Pueblo, Antonio ROVIRA VIÑAS (dir.), colección Monografías Aranzadi, nº 231, Defensor del Pueblo y Thomson, editorial Aranzadi, Cizur Menor, p.767). 
se mantiene en un régimen de cooperación ${ }^{20}$. En concreto, el artículo 28 de su Reglamento se refiere a la función de alta coordinación entre sus competencias propias y aquellas atribuidas a las defensorías autonómica, sin perjuicio de la autonomía que les corresponda en la fiscalización de la actividad de las Administraciones autonómicas, y determina la imposibilidad en la delegación de sus atribuciones constitucionales a estos órganos autonómicos. A partir de ahí, la Ley orgánica 36/1985 regula en su artículo 3 la posibilidad de que el Defensor suscriba acuerdos de cooperación y coordinación con las distintas instituciones autonómicas; unos acuerdos de colaboración que han sido empleados para suplir algunas de sus lagunas competenciales - como la falta de previsión estatutaria sobre la supervisión de la Administración local de algunos defensores autonómicos-. En todo caso, la doctrina cuestiona su utilidad ante la falta de aplicación en la práctica ${ }^{21}$ y subraya la evolución que han ido experimentando esas relaciones a lo largo del tiempo - que, desde una incuestionada posición preeminente del Defensor del Pueblo asociada a la función de coordinación - han supuesto en la actualidad el reconocimiento de meras facultades de coopera-

20 Debe añadirse que la Sentencia del Tribunal Constitucional 157/1988, de 15 de septiembre, de forma clara se pronuncia sobre el contenido de este artículo. Así, sobre la posible inconstitucionalidad del artículo 2.1 de la Ley estatal 36/1985 de relaciones del Defensor del Pueblo con instituciones similares en relación con la competencia de fiscalización de los Entes Locales sobre materias estatutarias, determina que este precepto simplemente fija los supuestos de cooperación entre el Defensor del Pueblo y las similares figuras autonómicas, sin llegar a regular el ámbito competencial de las distintas defensorías del pueblo.

21 FERNÁNDEZ RODRÍGUEZ añade que, pese a la importancia teórica de estos convenios en las relaciones recíprocas - ya que recogen las técnicas de coordinación formal como son las reuniones, comunicaciones y coordinación de sus sistemas informáticos-, puede decirse que están en gran parte superados por la dinámica personal de las instituciones (Cfr.,FERNÁNDEZ RODRÍGUEZ, J. J.: Defensorías del Pueblo en España: Una visión prospectiva, Cuadernos de democracia y derechos humanos, $\mathrm{n}^{\circ} 11$, Cátedra de Democracia y Derechos Humanos, Universidad de Alcalá de Henares, 2013, pp. 143 y 144). 
ción del Alto Comisionado de las Cortes en un régimen paritario con las figuras autonómicas bajo el paraguas de los estatutos de nueva generación ${ }^{22} \sin$ que con ello se resuelvan los problemas descritos.

En aras de una mayor eficacia en su actuación y con el fin de solucionar el problema de la delimitación competencial de las Defensorías del Pueblo en España, autores como BASTIDA FREIJEDO proponen que el Defensor del Pueblo debería restringir su ámbito de actuación a la Administración no periférica del Estado y, en lo demás, centrar su acción en la coordinación de las defensorías, actuando con carácter subsidiario cuando las quejas y reclamaciones se fundamenten en una inactividad o falta de eficacia de las defensorías autonómicas ${ }^{23}$. Sin embargo, debe destacarse que, como acabamos de subrayar, el artículo 28.3 del Reglamento de la organización y funcionamiento del Defensor del Pueblo, parece oponerse a tal posibilidad al impedir la delegación a los órganos autonómicos similares la competencia atribuida en el artículo 54 de la Constitución. Por este motivo, GARCÍA ÁLVAREZ aboga por la supresión de este apartado tercero del artículo 28 alegando su incongruencia con los dos apartados anteriores ${ }^{24}$. En todo caso, nos hallamos ante una limitación que lejos de su desaparición ha sido ratificada por el Tribunal Constitucional en su Sentencia 46/2015 al determinar la nulidad de los preceptos la Ley del Parlamento de Cataluña 24/2009, de 23 diciembre, del Síndic de Greuges que atribuyen a la defensoría autonómica la condición de autoridad

22 Cfr., FERnÁndeZ RODRÍGUEZ, J. J.: "Defensor del Pueblo y defensorías autonómicas: Reflexiones sobre sus relaciones y posición recíproca", Revista Teoría y Realidad Constitucional, n²6, UNED, Madrid, 2010, p.263.

$23 C f r$., BASTIDA FREIJEDO, F.J en $A A . V V$ : "Encuesta sobre el Defensor del Pueblo", en la Revista Teoría y Realidad Constitucional, n²6, UNED, Madrid, 2010, p. 45.

$24 C f r$., GARCÍA ÁlVAREZ, M. en $A A . V V$ : "Encuesta sobre el Defensor del Pueblo", en la Revista Teoría y Realidad Constitucional, n²6, UNED, Madrid, 2010, p.38. 
catalana para la prevención de la tortura y de otros tratos o penas crueles, inhumanos o degradantes ${ }^{25}$.

Finalmente, debemos señalar que un ejercicio eficaz de la actividad de supervisión requiere un consecuente deber de auxilio. Así, para posibilitar el ejercicio de sus funciones, la norma reguladora del Defensor del Pueblo determina que todos los poderes públicos están obligados a prestarle auxilio con carácter preferente y urgente en sus investigaciones e inspecciones pudiendo solicitarles todos los documentos necesarios para el desarrollo de su función. Nos encontramos ante nuevo problema de indeterminación que se extiende no sólo sobre los sujetos pasivos y el ámbito material objeto de supervisión por el Defensor del Pueblo, como acabamos de ver, si no que también afecta a la definición de los comportamientos de los funcionarios y/o autoridades que obstaculizan el normal desarrollo de su trabajo de investigación y supervisión. De este modo, debemos incluir en este apartado una breve referencia al bien jurídico protegido por el delito de obstaculización a las actuaciones del Defensor del Pueblo, tipificado en el artículo 502.2 del Código Penal ya que permite al Defensor del Pueblo disponer de un importante elemento coactivo a la hora de desempeñar su función de inspección respecto a las actividades de las administraciones públicas: la denuncia ante el Fiscal de la comisión de este delito de obstrucción. Como subraya VÁZQUEZ-PORTOMEÑE

25 En la Sentencia 46/2015 el Tribunal determina la nulidad parcial de la norma y circunscribe la acción del Síndic de Greuges dentro de los límites que determina el propio Estatuto catalán y el art. 149.1.3 de la Constitución. Es decir, lo define, a tales efectos, como un órgano con facultades de supervisión exclusivamente pero no con carácter exclusivo sobre la Administración de la Generalitat y la Administración local de Cataluña, y, concretamente, en relación con la prevención de la tortura, otros tratos o penas crueles, inhumanos o degradantes. Así, el Tribunal Constitucional entiende que, más allá de su designación como mecanismo nacional de prevención de la tortura, el Defensor del Pueblo, puede recabar, en su caso, la colaboración de la defensoría autonómica para la mejor eficacia de sus gestiones y recibir las quejas que le hubieran sido remitidas sobre la actividad de los órganos de la Administración pública estatal. 
SEIJAS, la criminalización de estos comportamientos se ha de valorar positivamente como una garantía técnico-jurídica al servicio del concepto de buena administración y, al mismo tiempo, como principio rector de la actuación administrativa integrador de un conjunto de derechos de los ciudadanos en sus relaciones con las administraciones públicas. Por este motivo, la tarea de delimitación del ámbito de tutela debe examinarse a partir de la descripción típica contenida en el artículo 502. 2 Código Penal así como su interpretación sistemática — por lo que estaría sujeto al mismo régimen punitivo que el delito de incomparecencia ante comisión parlamentaria de investigación regulado en el apartado primero del mismo artículo, el 502. 1 del Código Penal- . Un deber de colaboración del funcionario que se enmarca dentro del deber de auxilio de todos los poderes públicos establecido a partir del artículo 54 de la Constitución y configurado en los artículos 18, 19.1, 19.2, 19.3 y 25 de la Ley orgánica del Defensor del Pueblo y que condiciona, desde un punto de vista procedimental, la eficacia de este instrumento como mecanismo de control cuyo principal objeto es el de obtener información sobre la actividad fiscalizada. De este modo, se limita el efecto último de acción del Defensor del Pueblo: el de la presión política que produce la publicidad y difusión de sus informes ante la opinión pública; si bien el injusto típico, que expresa el fundamento último de la figura penal, no guarda relación alguna con el informe en que se plasme el resultado de la investigación como se deduce del hecho de que el legislador penal no lo incluye como un elemento del tipo con valor agravatorio $^{26}$.

En definitiva, a la luz de expuesto, observamos que nuestro ordenamiento jurídico configura al Defensor del Pueblo

$26 C f r$., VÁZQUEZ-PORTOMEÑE SEIJAS, F.: "Sobre el bien jurídico protegido por el delito de obstaculización a las actuaciones del Defensor del Pueblo (Art. 502.2 CP)", Revista Electrónica de Ciencia Penal y Criminología (RECPC), $\mathrm{n}^{\circ} 14-15,2012$, pp. 15:7, 15:8, 15:14 y 15:16. (http://criminet. ugr.es/recpc/14/recpc14-15.pdf, página web consultada 17/07/2017 a las 09.40h) 
como una magistratura de persuasión ${ }^{27}$ un instrumento limitado competencialmente y particularmente indeterminado a la hora de fiscalizar la actuación administrativa. Una limitación que se ve exponencialmente incrementada en el caso de las defensorías autonómicas. Nos encontramos ante una figura dinámica muy interesante para la mejora de la calidad democrática pero que requiere una serie de mejoras y actualizaciones con el fin de elevar su rendimiento institucional y eficacia al mismo tiempo que lo autolegitiman en el presente y futuro ${ }^{28}$.

El primero de los retos que deben hacer frente las defensorías autonómicas es el del peligro de su desaparición y la mejora de su coordinación nacional e internacional. La duplicidad de funciones con el Defensor del Pueblo en su labor de control de las administraciones públicas ${ }^{29}$, la promoción de la consoli-

27 En este sentido, CARBALLO MARTÍNEZ define al Defensor del Pueblo como una categoría especial de autoridad desprovista de privilegios de autotutela que tiene la Administración — prerrogativa, ejecutividad y ejecutoriedad - como derivación de una autoridad fáctica de legitimación jurídico constitucional cuyas atribuciones de investigación e inspección provienen de una legitimación del poder basada en la pretensión de obligar a una conducta ajena (Cfr. CARBALLO MARTÍNEZ, G.: La mediación administrativa y el Defensor del Pueblo, Thomson-Aranzadi, Cizur Menor, 2008, pp.257-258).

28 La dimensión de la calidad democrática de las defensorías se concreta tanto en su origen parlamentario, como en sus atribuciones competenciales en la resolución de quejas, la rendición de cuentas ante el Parlamento, los debates públicos que suscitan sus actuaciones, la naturaleza pro ciudadano y pro libertare de sus actuaciones, sus acciones pedagógicas y de difusión de derechos, el impulso de posibilidades participativas de la ciudadanía, en la promoción de la igualdad, como refuerzo del pluralismo en órganos e instituciones, al configurarse como una institución flexible para la promoción de la democracia deliberaría y que ayuda a construir una opinión pública en permanente contacto con entidades del tercer sector conocedoras de la realidad social, etc. (Cfr., FERNÁNDEZ RODRÍGUEZ, J. J.: Defensorías del Pueblo en España: Una visión prospectiva, Cuadernos de democracia y derechos humanos, $\mathrm{n}^{\circ} 11$, Cátedra de Democracia y Derechos Humanos, Universidad de Alcalá de Henares, 2013, pp.24, 59, 60, 61 y 62).

29 Recordemos que la Sentencia del Tribunal Constitucional sobre el Estatuto catalán 31/2010 declaró inconstitucional, en virtud de un recurso de 
dación presupuestaria y la sostenibilidad financiera supusieron la supresión en el año 2013 de los defensores autonómicos de Castilla La Mancha, La Rioja, el Principado de Asturias y la Región de Murcia, por lo que en la actualidad sólo nueve Comunidades Autónomas cuentan con esta figura - Andalucía, Aragón, Canarias, Castilla-León, Cataluña, Comunidad Valenciana, Galicia, Navarra y País Vasco-. En esta línea debe señalarse que se plantea también la necesidad potenciar su consolidación a través de la mejora de la coordinación interna e internacional entre los ombusdmen y su participación en organismos públicos que permitan encontrar soluciones efectivas a los problemas que trascienden a su ámbito de actuación y que lo configuren como un verdadero mecanismo de control.

En segundo término, con el fin de fortalecer su posición jurídica, cabe plantearse la necesidad de perfilar de forma clara su ámbito competencial que en muchas ocasiones se encuentra disperso en la normativa autonómica y que pueden generar problemas de indefinición o de falta de actualización - como ocurre con implementación de la administración electrónicalo que condiciona la eficacia de su actuación. La definición precisa y la actualización de sus funciones a las nuevas necesidades sociales y de calidad democrática emergen como prioridades normativas. El principio de transparencia se convierte en la pieza clave sobre la que se articula el funcionamiento del sector público y de sus instituciones por lo que las defensorías deben

\footnotetext{
inconstitucionalidad planteado por el Defensor del Pueblo, la pretensión estatutaria de convertir al Síndic de Greuges en el supervisor exclusivo de la administración autónoma catalana por ser incompatible con las previsiones del artículo 54 de la Constitución que no circunscribe la labor de control del Defensor del Pueblo al ámbito de la Administración General del Estado. Sobre la importancia de preservar su independencia y competencia en este ámbito lejos de las interferencias de los partidos políticos en la interposición de recursos de inconstitucionalidad debe consultarse. COLOMER VIADEL, A.: "La independencia del Defensor del Pueblo frente a los partidos políticos", Revista Teoría y Realidad Constitucional, n²6, UNED, Madrid, 2010, pp.365-366.. (https://dialnet.unirioja.es/descarga/articulo/3333194. $p d f$ página web consultada el 26/09/2017 a las 20.53h).
} 
controlar su cumplimiento por los poderes públicos. El empleo de las nuevas tecnologías de la información se convierte en un instrumento útil en este ámbito ya que no sólo permiten articular un buen gobierno si no también la difusión y el desarrollo de la función pedagógica social de las defensorías. Su acercamiento e interacción con la ciudadanía se plantea como una necesidad estructural sólo así puede plantearse la posibilidad de ampliar sus ámbitos de actuación sobre materias como los derechos sociales en situación de crisis, los derechos de las mujeres, las exigencias medioambientales, etc $^{30}$.

Finalmente, con el fin de una mejora de la calidad democrática de nuestro sistema político, como tercer reto debe plantearse la redefinición de la institución en la que se incorporen nuevos mecanismos de protección de los derechos fundamentales y de reacción ante las novedosas formas de vulneración. La transformación de la sociedad plantea en la actualidad nuevos instrumentos de participación directa con el fin de limitar el sesgo que se produce entre la actividad del gobernante, bajo una administración sobre dimensionada, y la confianza ciudadana. Es necesario replantear las actuaciones de las defensorías con el fin de intensificar su legitimidad en la defensa de los derechos de los ciudadanos. De nuevo, la supervisión del cumplimiento del principio de transparencia y buen gobierno por esta institución se convierte en una garantía en la protección del derecho al acceso a la información pública en todos los niveles y en toda actividad por parte de los ciudadanos lo que requiere una aplicación efectiva. Se plantea, así, el reto de su articulación como medida eficaz en la lucha contra la corrupción política. En último término, no podemos obviar que la falta de una solución a los problemas subrayados puede suponer un condicionante a la

30 Sobre los nuevos o renovados ámbitos de decisión material de las defensorías puede consultarse FERNÁNDEZ RODRÍGUEZ, J. J.: Defensorías del Pueblo en España: Una visión prospectiva, Cuadernos de democracia y derechos humanos, ${ }^{\circ} 11$, Cátedra de Democracia y Derechos Humanos, Universidad de Alcalá de Henares, 2013, pp. 85 y ss. 
hora de superar los nuevos retos que se le presentan a la institución en este ámbito y que, por su importancia, requieren una mención específica.

\section{EI Valedor do Pobo como instrumento político de transparencia y buen gobierno a partir de la}

\section{Ley gallega 1/2016}

A lo largo de los anteriores apartados nos hemos detenido en el estudio, con carácter general, de la configuración jurídica del Defensor del Pueblo y de las Defensorías autonómicas y de sus potencialidades para la mejora de la calidad democrática. Determinadas las principales notas identificativas que definen su función fiscalizadora del sobre la Administración pública, nuestro análisis se enfoca en las medidas singulares adoptadas para articular a las defensorías como instrumento de lucha ante la corrupción pública. En concreto, a continuación abordaremos la peculiar configuración que experimenta la figura del Valedor do Pobo a raíz de la Ley gallega 1/2016, de 18 de enero, de transparencia y buen gobierno.

Como hemos sostenido, la transparencia exige unos deberes de publicidad activa de la información —institucional, organizativa y de planificación - por parte de los responsables públicos. La creciente demanda de un control público de la actividad de las instituciones conlleva una apertura de los organismos públicos a la ciudadanía. Así, con el fin de verificar su cumplimiento se plantea la necesidad de establecer no sólo un portal de transparencia si no que se crea por la normativa estatal un órgano específico de control, el Consejo de Transparencia y Buen Gobierno ${ }^{31}$.

31 Cfr., Los artículos 33 a 40 de la Ley 19/2013, de 9 de diciembre, de transparencia, acceso a la información y buen gobierno en los que se regula este órgano así como el artículo 24 de esta norma en el que se articula el procedimiento de reclamación. 
El Título III de la Ley 19/2013, de 9 de diciembre, de transparencia, acceso a la información y buen gobierno da cobijo a la creación de esta nueva autoridad administrativa a la que se le encargan las funciones de promoción de la transparencia de la actividad pública, de velar por el cumplimento de las obligaciones de publicidad, de protección del ejercicio del derecho de acceso a la información pública y de garantía en la observancia de las disposiciones de Buen Gobierno. La Ley reguladora de la jurisdicción contencioso administrativa y del procedimiento administrativo común no contenía ninguna previsión específica respecto a las garantías del derecho de acceso, motivo por el que su protección se articulaba por el sistema ordinario de recursos administrativos y contencioso-administrativo. Autores como GUICHOT avalan este mecanismo ya que sostienen que la creación en el ámbito estatal de una nueva institución colegiada de nombramiento parlamentario de acceso a la información permite, en el ámbito de su autoorganización de las Comunidades Autónomas, fijar el modelo más eficaz y adecuado de fusión de sus competencias con las de protección de datos desde un punto de vista jurídico y económico ${ }^{32}$.

32 Un resultado que no se alcanzaba al atribuir estas competencias a organismos e instituciones ya existentes. Por un lado, siguiendo el modelo inglés o alemán, la atribución de esta competencia sobre transparencia y acceso a la información pública a una única agencia, la Agencia Española de Protección de Datos, requería introducir una nueva cultura, integrarla como una entidad de transparencia y protección de datos, lo que supondría dotarla de nuevos medios personales y materiales que supondría una duplicidad de costes al incrementarse sus competencias. Por otro lado, la solución inicial adoptada en los anteproyectos y proyectos de la Ley de transparencia, de encomendar estas atribuciones a una entidad ya creada, la Agencia estatal de Evaluación de las Políticas Públicas y de Calidad de los Servicios, aunque su ámbito competencial parecería comprender la transparencia de actividad pública, sin embargo, planteaba el problema de la independencia de la Institución al estar limitada su autonomía de gestión y funcional a lo previsto por la ley de agencias estatales y pos su estatuto, regulado en el Real Decreto 1418/2006 (Cfr. GUICHOT REINA, E.: "El Consejo de Transparencia y Buen Gobierno" en VV.AA. Transparencia, Acceso a la Información Pública y Buen Gobierno. Estudio de la Ley 19/2013, de 9 de diciembre, E. GUICHOT (Coord.), colección práctica jurídica, editorial Tecnos, Madrid, 2014, pp. 335-337). 
Conforme al artículo 33 de la Ley 19/2013, nos encontramos ante un ejemplo de Administración independiente adscrito al Ministerio de Hacienda y Administraciones Públicas, a efectos de su diseño y tramitación de su presupuesto pero no depende de éste, desde un punto de vista orgánico o funcional. Este Consejo está compuesto de dos órganos: la Comisión y el Presidente. Si bien la Ley establece la remuneración económica y exige dedicación exclusiva del Presidente, no ocurre lo mismo con los demás miembros de la Comisión. La elección del Presidente por mandato de cinco años no renovable y por una mayoría parlamentaria cualificada pueden suponer una garantía de independencia, legitimidad y eficacia al evitar su coincidencia entre legislaturas y al exigir un mayor consenso político. Una independencia que se refuerza también desde el punto de vista orgánico a la hora de determinar los miembros que conforman la Comisión. Este órgano colegiado está integrado por el Presidente, dos representantes de los poderes del Estado - legislativo y ejecutivo- $-\mathrm{y}$ otras instituciones constitucionales adscritas al legislativo - como el Defensor del Pueblo o el Tribunal de Cuentas-, así como autoridades independientes de control - como son la Agencia Española de Protección de Datos y la Autoridad Independiente de Responsabilidad Fiscal - pero que, en todo caso, no incluye representantes de la sociedad civil. Sorprende observar que la norma distingue entre funciones de la Institución y su órgano unipersonal - las correspondientes al Consejo y al Presidente- y no diferencia entre las funciones entre sus órganos - Comisión y Presidente-. En todo caso, aunque pueden ser ampliadas mediante una cláusula abierta de cierre, las atribuciones que se reconocen explícitamente al Consejo son funciones de recomendación, asesoramiento, promoción e información incluidos los proyectos normativos estatales que desarrollen la Ley o estén relacionados con su objeto. Mientras que las funciones del Presidente son más concretas y revisten de mayor poder político y jurídico ya que se extienden sobre la adopción de criterios de interpretación de las obligaciones recogidos en la Ley, la supervisión de su cumplimiento legal, el 
conocimiento de las reclamaciones presentadas conforme al artículo 24 de la norma ${ }^{33}$, responder a las consultas presentadas por los órganos que tramiten o resuelvan las solicitudes de acceso a la información, instar de oficio el procedimiento sancionador o aprobar el anteproyecto de presupuesto. Como contrapartida, esta concentración de poder en la figura del Presidente condiciona la efectividad del órgano a la persona que ostente el cargo y exige que se extremen las garantías de independencia en su elección para que realmente nos encontremos ante un verdadero órgano de control eficaz de la transparencia y buen gobierno de la actividad administrativa.

Una autonomía decisional que aparece condicionada en la Ley 19/2013, ya que su artículo 24 precisa que la competencia del Consejo para conocer de las reclamaciones se excepciona en los supuestos en los que las Comunidades Autónomas atribuyan esa competencia a un órgano específico conforme a su disposición adicional cuarta. Es decir, la norma admite la adopción de un modelo heterogéneo en el que nos encontramos con un grupo de Comunidades Autónomas que han suscrito un convenio con el Consejo estatal de Transparencia y Buen Gobierno - es el caso de Asturias, Cantabria, Castilla-la Mancha, La Rioja, Extremadura y Ceuta-; un segundo grupo mayoritario de Comunidades Autónomas que crean un órgano específico al que se le encomienda esta función - como ocurre con Andalucía, Aragón, Cataluña, Canarias y Valencia-; y finalmente, otras Comunidades Autónomas han atribuido estás facultades al defensor del pueblo autonómico — Castilla y León y Galicia-.

33 Sobre el procedimiento para el ejercicio del derecho a la información pública, en concreto, respecto a su tramitación conforme al artículo 24 de la Ley 19/2013 ante los tribunales o ante el Consejo de Transparencia y Buen Gobierno puede consultarse BARRERO, C.: "El derecho de acceso a la información: publicidad pasiva", en VV.AA. Transparencia, Acceso a la Información Pública y Buen Gobierno. Estudio de la Ley 19/2013, de 9 de diciembre, E. GUICHOT (Coord.), colección práctica jurídica, editorial Tecnos, Madrid, 2014, pp. 199-246. 
La comunidad autónoma de Galicia fue pionera a la hora de implantar medidas de transparencia y buenas prácticas en la Administración pública ${ }^{34}$ si bien su interconexión expresa con la función supervisora del Valedor do Pobo se materializa a través de la Ley gallega 1/2016. Como hemos subrayado, esta norma supone una adaptación de la normativa autonómica a la Ley estatal. A partir de la previsión estatutaria de esta figura ${ }^{35} \mathrm{y}$, con el fin de completar la institucionalización autonómica gallega, la Ley 6/1984, de 5 de julio regula, siguiendo las grandes líneas de la Ley orgánica del Defensor del Pueblo, al Valedor si bien procura, al mismo tiempo, ensanchar sus funciones. Así, el artículo 1 de la Ley del Valedor do Pobo lo define como Alto Comisionado del Parlamento de Galicia para la defensa, en el

34 En el ámbito gallego, dos leyes específicas ya habían abordado con carácter previo la rendición de cuentas: la Ley 9/1996, de 18 de octubre, de incompatibilidades de los miembros de la Xunta de Galicia y altos cargos de la Administración autonómica, y la Ley 4/2006, de 30 de junio, de transparencia y de buenas prácticas en la Administración pública gallega. Dos leyes que permitieron avanzar en el control de la actividad pública en Galicia. Así, la Ley 9/1996 fijó el primer régimen de incompatibilidades de los responsables públicos de Galicia con el fin de fijar las necesarias que garantizasen su objetividad e imparcialidad. Mientras que la Ley 4/2006 introdujo la transparencia como principio rector de la actividad de la Administración autonómica, una norma precursora ya que supuso la concreción legal de prácticas como la publicación de la información sobre los convenios y contratos públicos, las convocatorias de subvenciones y la resolución de estas o la información retributiva de los cargos públicos.

$35 C f r$., el artículo 14 del Estatuto de autonomía de Galicia en el que simplemente se establece, en relación con la regulación del Parlamento gallego que le corresponde a la Comunidad autónoma mediante ley de su Parlamento la creación de un órgano similar al Defensor del Pueblo estatal que ejerza sus funciones en coordinación con éste. Obsérvese que esta breve mención, a diferencia de la previsión constitucional relativa al Defensor del Pueblo, se inserta dentro del Título I relativo al poder gallego, en concreto, en el capítulo I que regula su Parlamento y no en relación con la previsión estatutaria relativa a los derechos y libertades de los gallegos contenidas en el artículo 4. Una ubicación que lejos de ser ignorada, puede interpretarse como un refuerzo en su relación con el poder legislativo autonómico y una limitación en la protección de los derechos al dar prioridad a su establecimiento y articulación competencial mediante ley parlamentaria. 
territorio autonómico de los derechos comprendidos en el Título I de la Constitución y en el Título preliminar del Estatuto ${ }^{36}$. Por este motivo, su nombramiento y cese depende de la cámara legislativa autonómica, cuyas relaciones se articulan a través de la Comisión de Peticiones del Parlamento. Para el desarrollo de sus funciones y en aras de su independencia, se configuran una serie de instrumentos bien orgánicos o bien funcionales como son: la disponibilidad de su propio aparato material y personal asesor, administrativo y funcionariado, independiente sin relación jerárquica respecto al legislativo - conforme a los artículos 8, 9 y 10 de la Ley que regula la institución-; la previsión de una partida específica en el Presupuesto del Parlamento gallego -reconocida en el artículo 12 de la Ley del Valedor-; el no sometimiento a mandato imperativo ninguno - como establece el artículo 6 de la Ley 6/1984-; su estatuto personal en el que se determina su incompatibilidad con todo cargo político, público o profesional — de acuerdo con el artículo 7- así como una régimen de garantías de inmunidad e inviolabilidad — recogidas en el artículo 11 - que son comunes a las reconocidas a los parlamentarios gallegos. Por este motivo, podemos señalar que nos encontramos ante una institución conexa al Parlamento gallego - ante el que debe presentar anualmente un informe preceptivo de su actividad - pero, al mismo tiempo, es una figura autónoma que expresa una voluntad propia, específica y diferenciada del órgano que lo nombra ${ }^{37}$ y que pretende ser preservada de toda influencia política al ser nombrado por mayoría parlamentaria de tres quintos por un mandato de cinco años.

36 Puede consultarse una enumeración exhaustiva de los derechos cuya defensa se le encomienda al Valedor do Pobo a partir de esa atribución genérica en CORA RODRÍGUEZ, J.: "O Valedor do Pobo" Estudios sobre o Estatuto Galego, J. RODRÍGUEZ-ARANA MÚÑ̃Z(coord.), Escola Galega de Admininistracoión Pública (EGAP), Santiago de Compostela, 1991, pp.344-345.

37 Cfr. MAIZ SUÁREZ, R.: "Artículo 14" en Comentarios al Estatuto de Autonomía de la Comunidad Autónoma de Galicia, J.L. CARRO FERNÁNDEZ-VALMAYOR (coord.), colección legislación y jurisprudencia, Ministerio para las Administraciones Públicas, Instituto Nacional de Administración Pública (INAP), Madrid, 1991, pp.171-172. 
Como hemos visto en relación con el Defensor del Pueblo su actividad es en parte de mediación ante la Administración $\mathrm{y}$ en parte de investigación de la propia acción administrativa ${ }^{38}$. La configuración del Valedor do Pobo como garantía jurídica en la supervisión de la actividad administrativa plantea la necesidad de verificar tres elementos principales: la autonomía institucional, una definida delimitación competencial y el poder de coercitivo de sus resoluciones. Tres elementos que determinan la configuración de un instrumento político y jurídico eficaz en la lucha contra la corrupción política y que, a la luz de la Ley $1 / 2016$, debemos analizar de manera interrelacionarse ya que se exigen respectivamente a la hora de establecer un control sin fisuras de la actividad administrativa.

La autonomía se convierte, de nuevo, en una pieza clave, a la hora de definir, la eficacia de su función si bien en el caso del Defensor autonómico gallego destacaremos que su independencia no sólo ha de garantizarse respecto a las instituciones autonómicas si no que también es necesario definir sus actuaciones en relación con el Defensor del Pueblo. Debe subrayarse que el ámbito de intervención del Valedor do Pobo es muy limitado y que se plantean ciertos problemas de deslinde competencial. Conforme al artículo 1.2 y 1.3 de la Ley del Valedor, éste sólo puede supervisar la actividad de la Administración de la Comunidad gallega y de sus agentes y empresas públicas o dependientes así como de la Administración local en las materias que son competencia gallega. El empleo de esta locución en la Ley 6/1984 plantea algún problema de delimitación en sus atribuciones que intentó solucionarse con una reforma legislativa operada mediante la Ley 3/1994, de 18 de julio. Por un lado, puede entenderse que el artículo 12 de la Ley del Defensor del Pueblo, al atribuirle la competencia de supervisión de la actividad de la Comunidad autónoma, le otorga al Defensor estatal un poder general de control sobre la Administración del Estado que se extiende

38 Cfr., PÉREZ ROYO, J.: Curso de Derecho Constitucional, (Decimocuarta edición), Marcial Pons, Madrid, 2014, p.474. 
sobre la Administración en la Comunidad autónoma por lo que puede supervisar tanto la Administración autonómica como el funcionamiento administrativo del Parlamento de Galicia o del Tribunal Superior de Justicia de Galicia. Por otro lado, el poder de supervisión del Valedor do Pobo sobre la Administración local gallega, abarca al ejercicio de las competencias que corresponden a Galicia, es decir, aunque no se especifique claramente están incluidas en su ámbito competencial las materias propias y delegadas por la Comunidad autónoma ${ }^{39}$. En todo caso, el Alto Comisionado del Parlamento gallego se configura como una institución que ejerce funciones de persuasión y no coercitivas que pretenden corregir la acción de la Administración autonómica y local en Galicia.

Con el fin de garantizar la eficacia de sus actuaciones, el artículo 26 de la Ley del Valedor establece la obligatoriedad de todos los poderes públicos autonómicos requeridos de prestar auxilio y cooperación en el curso de sus investigaciones. De manera que a efectos de sus averiguaciones, puede presentarse en cualquier instalación dependiente de la Administración autonómica de la Comunidad autónoma para realizar entrevistas personales o consulta de documentación sin que se le pueda negar su acceso aunque se trate de documentos secretos, salvo que medie acuerdo de la Xunta. Pero ese deber de cooperación tiene un alcance limitado ya que en que en supuesto de que existan dificultades que lo impidan o en caso de negativa, el Valedor carece de poder coercitivo alguno ya que sólo puede hacerlo público en su informe anual o dar cuenta al superior jerárquico o, en último término, al Ministerio Fiscal para el ejercicio de las acciones procedentes — conforme al artículo 22 de la Ley del Valedor-

39 Cfr. MAIZ SUÁREZ, R.: "Artículo 14" en Comentarios al Estatuto de Autonomía de la Comunidad Autónoma de Galicia, J.L. CARRO FERNÁNDEZ-VALMAYOR (coord.), colección legislación y jurisprudencia, Ministerio para las Administraciones Públicas, Instituto Nacional de Administración Pública (INAP), Madrid, 1991, pp.176-177. 
Es decir, la actividad del Valedor do Pobo como mecanismo de control es limitada, se articula sobre la base del principio de cooperación no sólo con los poderes públicos autonómicos si no también con el Defensor del Pueblo y con el resto de defensorías autonómicas - aunque en este último caso la colaboración vendrá mediatizada por el Defensor del Pueblo tal y como establece el artículo 16.3 de la Ley gallega-. Observamos así que los condicionantes descritos en líneas anteriores sobre sus funciones, competencias y la necesidad de una articulación colaboradora de las defensorías se verifican también respecto a la figura del Valedor. La necesidad su independencia se ve agravada cuando sus prerrogativas no aparecen garantizadas en sede estatutaria si no que se reconocen en los artículos 6 y 7 de la Ley gallega 6/1984, aún así, nos encontramos ante una norma de desarrollo básico estatutario que conforma el parámetro por el que se miden las demás leyes autonómicas ${ }^{40}$.

A pesar de las limitaciones funcionales señaladas, la Ley gallega 1/2016 opta por establecer a la figura del Valedor como mecanismo principal de control de las irregularidades producidas en la actividad de la Administración de la Comunidad autónoma de Galicia también en el ámbito de la transparencia y del buen gobierno. En concreto debemos referirnos a los artículos 32 y 33 de la Ley 1/2016 ya que amplían las facultades del Valedor al atribuirle no sólo las funciones de Presidente de la Comisión de Transparencia si no también las correspondientes al Comisionado de la Transparencia. De manera que, como Comisionado de Transparencia, el Valedor debe responder a las

40 Recordemos que RAMÓN FERNÁNDEZ entiende que la modificación del estatus jurídico personal de la Ley $36 / 1985$, requiere ser recogido en un precepto estatutario específico para que las prerrogativas reconocidas a los defensores autonómicos sean constitucionales ( $C f r$. RAMÓN FERNÁNDEZ, T. en AA.VV: "Encuesta sobre el Defensor del Pueblo", en la Revista Teoría y Realidad Constitucional, $n^{\circ} 26$, UNED, Madrid, 2010, p. 39). Un interpretación extensiva, nos permite afirmar que el carácter de norma institucional básica de la Ley gallega 6/1984 no parece ser contrario a este requisito por lo que su reconocimiento debe entenderse otorgado. 
consultas que, con carácter facultativo, le formulen los sujetos incluidos en el ámbito de aplicación de la ley ${ }^{41}$; una vez oída la Comisión de transparencia, debe adoptar recomendaciones para un mejor cumplimiento de las obligaciones legales establecidas en materia de transparencia y buen gobierno; tiene la facultad de asesorar en materia de transparencia del derecho de acceso a la información pública y buen gobierno; oída la Comisión de la Transparencia, también está facultado para emitir informes, con carácter previo a su aprobación, sobre proyectos de ley o de reglamentos en materia de transparencia y buen gobierno; en último término efectúa, a iniciativa propia o a causa de denuncia, requerimientos para la subsanar los incumplimientos que pudieran producirse de las obligaciones de publicidad activa previstas en la Ley $1 / 2016$.

41 En el artículo 3 de la Ley 1/2016, de 18 de enero de transparencia y buen gobierno se indica que el ámbito subjetivo de la norma se extiende de un modo amplio al sector público gallego y sus entidades instrumentales; las universidades del sistema universitarios de Galicia así como las entidades vinculadas o dependientes de las mismas; las corporaciones de derecho público que desarrollen su actividad exclusivamente en el ámbito territorial gallego cuando se refiera a actividades sujetas a derecho administrativo; el Parlamento de Galicia, Consello Consultivo, Valedor do Pueblo, Consello de Contas, Consello Económico e Social, Consello Galego de Relaciones Laborais y Consello da Cultura Galega, en lo que se refiere también a las actividades sujetas a derecho administrativo y respecto de sus actos en materia de personal y contratación; los demás entes, organismos o entidades con personalidad jurídica propia creados específicamente para satisfacer necesidades de interés general que no tengan carácter industrial o mercantil, siempre que uno o varios de los sujetos públicos señalados financien mayoritariamente su actividad, controlen su gestión o nombren a más de la mitad de los miembros de su órgano de administración, dirección o vigilancia; o las asociaciones constituidas por los entes, organismos o entidades anteriores. Además, ese control abarcar a los partidos políticos, organizaciones sindicales, organizaciones empresariales y entidades privadas si éstos reciben fondos del sector público autonómico, por lo que también deben dar cumplimiento a sus obligaciones de publicidad en el Portal de transparencia y Gobierno abierto. En todo caso, las obligaciones de suministro de información se aplican a cualquier entidad privada que reciba o gestione fondos públicos o cuya actividad tenga interés público o repercusión social en los términos que acabamos de indicar, incluidas todas las personas físicas o jurídicas adjudicatarias de contratos o beneficiarias de subvenciones. 
Estas importantes competencias son susceptibles de ser ampliadas no sólo en el futuro mediante una disposición legal como prevé el artículo 32.3.f) de la norma comentada, sino que deben añadirse las correspondientes a la presidencia de la Comisión de Transparencia gallega. Nos encontramos ante un órgano colegiado que, aunque se identifica como independiente, se adscribe al Valedor do Pobo que lo preside mientras que uno de sus adjuntos actúa como vicepresidente del mismo. Esta Comisión tiene la atribución de resolver las reclamaciones que se presenten ante resoluciones de acceso a la información público, pudiendo el Valedor dirimir con su voto cualquier empate que se produzca. Finalmente, para completar las previsiones establecidas en la normativa estatal y también con carácter resolutorio, la Disposición adicional quinta de la Ley 1/2016 completa las atribuciones del Alto Comisionado Parlamentario gallego al establecer expresamente que, en el supuesto de resoluciones dictadas por las entidades locales de Galicia, es el Valedor el encargado su resolver las reclamaciones presentadas conforme al artículo 24 de la Ley estatal 19/2013.

Consciente de las importantes funciones atribuidas a esta institución, la norma gallega prevé una serie de medidas tendentes a garantizar su cumplimiento pero que pueden ser cuestionadas a efectos de eficacia funcional y falta de coercibilidad en sus actuaciones que redunda en lo manifestado en líneas anteriores.

Así, en primer lugar respecto a los medios disponibles, cabe destacar que la disposición adicional sexta señala la necesidad de reordenar y reasignar los medios personales y materiales de la institución y, debe añadirse que el artículo 34, de forma expresa, determina la separación de funciones y medios personales y materiales del Comisionado de la Transparencia y de la Comisión de Transparencia respecto a las demás que correspondan al Valedor si bien se establece que podrá disponer de ellos. Esta previsión normativa parece que complica en la práctica la definición precisa de los contornos de esa diferenciación dado que nos encontramos ante medios que son reordenador y a los que se le atribuyen funciones distintas pero al mismo tiempo se 
reconoce que también el Valedor podrá disponer de ellos por lo que no está claro el porqué diferenciarlos.

En segundo término, respecto a los sujetos obligados al cumplimiento de los deberes de transparencia y buen gobierno, la Ley 1/2016 simplemente hace referencia en su artículo 35 a una prestación de colaboración necesaria y a la facilitación de la información requerida por el Valedor así como el traslado del Informe de anual de transparencia emitido por la Comisión Interdepartamental de Información y Evaluación dependiente de la Xunta de Galicia. Como contrapartida, y como una garantía mínima simplemente en los artículos 28.3 y 35, se prevé que las resoluciones del Valedor del Pueblo por las que se resuelven las reclamaciones de acceso a la información pública tan sólo se publicarán en el Portal de transparencia y Gobierno abierto y deberán ser tenidas en cuenta por parte de los sujetos que hayan dictado las resoluciones objeto de reclamación; y que, a efectos de publicidad en el cumplimiento de la Ley, el Valedor debe incluir en el informe anual que presente ante el Parlamento gallego un apartado específico relativo a la transparencia y ponerlo a disposición de los ciudadanos on line. De este modo surgen dudas respecto a la fuerza coercitiva que pueden tener las resoluciones adoptadas en este ámbito. No podemos olvidarnos que, dentro del apartado de delitos contra las instituciones del Estado, el artículo 502.2 del Código Penal se configura como un elemento coactivo indirecto previsto a disposición del Defensor del Pueblo en la medida en que éste puede denunciar ante el Fiscal la actuación obstaculizadora de funcionarios y autoridades. Un instrumento que adolece de dos problemas. Por un lado, el de su fundamentación jurídica ya que, aunque también es puesto a disposición del Valedor do Pobo como órgano equivalente en la comunidad, no tiene una fundamentación constitucional expre$\mathrm{sa}^{42}$. Por otro lado, el tipo de conductas a las que se refiere este tipo penal son las de obstrucción a las investigaciones, es decir,

42 Esa fundamentación en el caso del Valedor do Pobo se localiza en el artículo 14 del Estatuto de autonomía por lo que naturaleza es estatutaria sin 
se refiere a la fase inicial de investigación, pero no comprenden las del incumplimiento de sus resoluciones, una vez concluida y emitido el informe, por este motivo, en los artículos 52 a 61 de la Ley $1 / 2016$ que regulan el régimen sancionador no se hace ninguna referencia a la figura del Valedor.

En este sentido, no podemos obviar que la adopción por la Ley gallega de un modelo de control de transparencia protagonizado por la figura del Valedor supone, en todo caso, una mutación para esta materia dada la naturaleza no ejecutiva de sus resoluciones. Como resalta GUICHOT, la clave para valorar la adecuación de esta fórmula se mide, en tercer lugar, en términos de garantía de la cualificación e independencia de la figura del Valedor do Pobo. La cualificación exige que la persona que ostente el cargo tenga experiencia en la materia y la independencia conlleva a garantizar su elección por mayoría cualificada parlamentaria, tasar sus causas de cese, limitar la duración y la renovación de los mandatos para evitar su influencia por los intereses de los partidos políticos ${ }^{43}$. Consideramos que entraña un grave riesgo para el funcionamiento adecuado de nuestro sistema político el hacer depender el prestigio y consideración del Valedor do Pobo como órgano autónomo y neutral sólo de la cualificación de la persona a efectos de su independencia de los

referencia alguna en el texto constitucional. Como nos recuerda el Profesor VÁZQUEZ-PORTOMEÑE SEIJAS, las acciones del Defensor Pueblo no se enmarcan en el contexto de una relación jerárquica ya que no es superior jerárquico de ninguna administración sino que atienden al deber de auxilio recogido en la Ley del Defensor del Pueblo - en concreto, en los artículos $18,19.1,19.2,19.3$ y 25 - cuyo último fundamento se encuentra en el artículo 54 de la Constitución. (Cfr. VÁZQUEZ-PORTOMEÑE SEIJAS, F.: "Sobre el bien jurídico protegido por el delito de obstaculización a las actuaciones del Defensor del Pueblo (Art. 502.2 CP)", Revista Electrónica de Ciencia Penal y Criminología (RECPC), no 14-15, 2012, p. 15:8. (http://criminet.ugr.es/recpc/14/recpc14-15.pdf, página web consultada 17/07/2017 a las 09.40h).

43 Cfr., GUICHOT REINA, E.: "Reflexiones acerca de la nueva normativa sobre transparencia pública" en Administración de Andalucía: revista Andalus de administración pública, $\mathrm{n}^{\circ} 94$, Universidad de Sevilla- Instituto andaluz de la Administración Pública, Sevilla, 2016, p.105. 
partidos políticos más aún en la lucha contra la corrupción pública. Es necesario extremar las garantías genéricas relativas al no sometimiento a mandato imperativo y la incompatibilidad con el mandato representativo - requeridas en el momento de la toma de posesión del cargo, no de su elección - así como otras manifestaciones específicas previstas en la Ley como la elección por una mayoría parlamentaria reforzada que expresa un consenso político que va más allá del partido mayoritario o mediante un sistema de elección secreto que confiere mayor independencia al diputado a la hora de emitir su voto. Aún así, somos conscientes de que la figura del Valedor do Pobo no es aséptica políticamente si no que su elección responde a cierta afinidad con una tendencia política mayoritaria en el Gobierno que apoyan al candidato a través de sus grupos parlamentarios. El sistema de elección se convierte en una pieza esencial ya que debe evitar que se convierta en una instrumento de la mayoría parlamentaria y al mismo tiempo debe reflejar el mayor consenso político posible sólo de este modo podremos afirmar que nos encontramos ante una verdadera garantía institucional de los derechos y de las libertades de los ciudadanos que actúa por encima del Parlamento, de los órganos clásicos de poder y de los partidos políticos ${ }^{44}$.

44 En esta línea, con el fin de garantizar en su independencia y para evitar los excesos de los partidos políticos, COLOMER VIADEL avanza un paso más en sus propuestas ya que plantea la posibilidad de que, mediante reforma constitucional, el Alto Comisionado parlamentario fuese elegido directamente por el Pueblo y no por las Cortes entre aquellos candidatos que no tuviesen un vínculo directo o contractual con los partidos políticos al menos en los últimos de diez años y, como un poder dual representativo del Pueblo más allá del Parlamento, pudiese promover la convocatoria de referéndum (Cfr. COLOMER VIADEL, A.: "La independencia del Defensor del Pueblo frente a los partidos políticos", Revista Teoría y Realidad Constitucional, n²6, UNED, Madrid, 2010, p. 366 (https://dialnet.unirioja.es/descarga/articulo/3333194.pdf página web consultada el 26/09/2017 a las 20.53h). En este sentido, el Profesor COLOMER propone que el Defensor pueda promover la convocatoria de referéndum popular sobre temas de especial relevancia, con el fin de aproximar al Alto Comisionado parlamentario, aunque débilmente, al espíritu inspirador del histórico Tribuno de la Plebe, y al «poder negativo» del pueblo, del que debe ser un instrumento institucional ( $C f r$. 
En último término, hay que añadir el problema de la falta de fuerza coercitiva de sus resoluciones así como el carácter disuasorio que pueda tener de cara a futuras irregularidades. Unos elementos que se han sido cuestionado a lo largo de este trabajo. Debe subrayarse que la norma admite una restricción más a la acción supervisora del Valedor ya que en sus artículos 25 y 28 se regulan posibles limitaciones al acceso a la información pública y a las reclamaciones que se interpongan por su incumplimiento. Unas restricciones al acceso que deben interpretarse de forma proporcionada y restrictiva y justificada ${ }^{45}$. Un un régimen que no afecta a los diputados autonómicos gallegos conforme al artículo 24.3 pero que, en todo caso, si se extiende

COLOMER VIADEL, A.: "El Defensor del Pueblo: un órgano políticoadministrativo de protección de los derechos", Revista de Derecho Político, n ${ }^{\circ} 70-71$, enero-agosto, UNED, Madrid, 2008, pp.62 y 73 (http://e-spacio. uned.es/fez/eserv.php? pid=bibliuned:DerechoPolitico2008-2\&dsID=PDF página web consultada 25/09/2017 a las 16.54 h). Pero lo cierto es que esta propuesta parece difícil que se materialice. El constituyente español ha alejado la posibilidad de promover un referéndum consultivo por la ciudadanía, el artículo 92.2 de la Constitución admite su participación indirecta a través de la aprobación por mayoría absoluta del Congreso de la propuesta presentada por el Presidente del Gobierno que debe ser elevada a Rey, único legitimado para su convocatoria. En este mismo sentido, en el artículo 2.1 de la Ley orgánica 3/1984, de 26 de marzo que regula la iniciativa legislativa popular, el legislador ha previsto su exclusión como procedimiento al entender que se trata de una materia regulada por Ley orgánica. De este modo, se bloquea la posibilidad de participación ciudadana en la promoción de los referenda lo que dificulta abrir la vía de la mediación del Defensor en este ámbito.

45 El artículo 25 de la Ley gallega 1/2016 determina expresamente que los límites al derecho a la información pública se aplican a los supuestos previstos en la normativa básica si bien admite que se aplicarán restrictivamente. Es decir, siempre que sea posible, se concederá el acceso parcial, omitiendo la información afectada por la limitación, salvo que la información resultante sea equívoca o carente de sentido; deben ser proporcionados atendiendo a su objeto y finalidad de protección; deben interpretarse de manera justificada y se aplicarán a menos que un interés público o privado superior justifique la divulgación de la información; y, finalmente, que solo serán de aplicación durante el periodo de tiempo determinado por las leyes o mientras se mantenga la razón que los justifique. 
al Valedor do Pobo y que excluye la posibilidad de acudir ante la defensoría autonómica gallega ante reclamaciones interpuestas frente a resoluciones de acceso a información pública dictadas por algunas instituciones. Así, se prevé expresamente que sólo procede la interposición de recurso contencioso-administrativo, cuando se trate de reclamaciones frente a resoluciones expresas o presuntas en materia de acceso a la información pública dictadas por el Parlamento de Galicia, Consello Consultivo, Consello de Contas, Consello Económico e Social, Consello Gallego de Relacións Laborais y Consello da Cultura Galega e, incluso del propio Valedor en relación con sus actividades sujetas a derecho administrativo y, en todo caso, respecto de sus actos en materia de personal y contratación.

De este modo, como acabamos de ver, el problema de la eficacia funcional de la acción de control del Valedor no sólo se verifica respecto al ámbito competencial establecido en la norma si no que la Ley 1/2016 plantea de forma clara una actuación muy limitada a la que se añade la falta de coercibilidad en las acciones que puede emprender el Valedor. Motivo por el que pueden plantearse dudas sobre si su capacidad de fiscalización se adapta a los cambios normativos experimentados por la Administración Pública un requisito que se plantea como necesario, a tenor de los dispuesto en el propio preámbulo de la Ley 1/2016, si el fin último que se pretende es garantizar la prestación de un buen servicio y un buen gobierno al administrado ${ }^{46}$.

El tiempo nos dirá si estás medidas son suficientes para garantizar el fin que persiguen pero nos surgen ciertas dudas de efectividad cuando no llevan aparejadas una mayor fuerza ejecutiva. Hacer pivotar un modelo de transparencia y buen gobier-

46 En este sentido GARCÍA ÁLVAREZ aboga por que cuestiones como la fiscalización de la actividad a administrativa de las Asambleas legislativas sean una materia susceptible de control por las defensorías autonómicas (Cfr., GARCÍA ÁLVAREZ, M. en $A A . V V$ : "Encuesta sobre el Defensor del Pueblo", en la Revista Teoria y Realidad Constitucional, n²6, UNED, Madrid, 2010, pp. 24, 25 y 46. 
no de la actividad de la Administración gallega sobre un mecanismo de supervisión con un alcance tan limitado puede plantear problemas en la consecución de sus objetivos últimos, la lucha contra la corrupción política. Más aún cuando sus labores son mayormente consultivas o asesoramiento ya que se limitan a verificar el cumplimiento de las obligaciones de publicidad activa de la información pública; responder a consultas que, con carácter facultativo le presenten las entes públicos afectados por la Ley; asesorar en materia de transparencia del derecho a la información pública; emitir recomendaciones para el cumplimento de las obligaciones fijadas en la norma o informes previos sobre proyectos de ley o reglamentos en este ámbito. Sus labores de supervisión específicas sobre el control de los Altos cargos se extienden sobre la consulta del registro de actividades de Altos cargos y de bienes patrimoniales, conforme a lo previsto en el artículo 49.2.d) de la Ley 1/2016 en el que se le reconoce la posibilidad de acceder por completo junto a la que le corresponde al Defensor del Pueblo.

Finalmente, hemos de ser conscientes de la verdadera dimensión que tiene la institución. GARCÍA ÁLVAREZ nos recuerda que un defensor contribuye a resolver cuestiones concretas planteadas por los ciudadanos, pero es ilusorio esperar que, como consecuencia de su trabajo, desaparezca la mala Administración ${ }^{47}$. Nos encontramos ante un instituto externo más de control para supervisar a la Administración defendiendo los derechos de los ciudadanos al que ahora se le atribuyen nuevas funciones en el ámbito de la transparencia y buen gobierno, pero no es el único. El Valedor do Pobo al igual que el Defensor del Pueblo carece de facultades para realizar por sí actos de ejecución de las resoluciones que acordase en el ámbito de su investigación, no dispone de potestas, su autoridad no forma parte de ningún poder. Para CARBALLO MARTÍNEZ esto no

$47 C f r$., GARCÍA ÁlVAREZ, M. en $A A . V V$ : "Encuesta sobre el Defensor del Pueblo", en la Revista Teoría y Realidad Constitucional, n²6, UNED, Madrid, 2010, pp.24 y 25. 
varía de contenido su autoridad si no que, sensu contrario, le otorga independencia de dicho poder al realizar una tarea interpretativa del Derecho no sujeta a mandato imperativo ${ }^{48}$, pero no podemos obviar que limita su eficacia como medida de control de transparencia, a un poder disuasorio que opera a partir de la publicidad de su informe anual, por lo que sus acciones debe complementarse con otras dotadas de mayor fuerza coercitiva.

Conviene recordar que el Poder Judicial, en concreto, la jurisdicción contencioso administrativo, no ha desaparecido como vía de garantía ante las vulneraciones de los derechos de los ciudadanos por la Administración. En virtud, del artículo 20.5 de la Ley estatal 19/2013, en el supuesto de resoluciones dictadas en materia de acceso a la información pública es posible acudir de forma directa a los tribunales contencioso administrativos, sin necesidad de intervenga previamente la autoridad independiente de control o bien tras la desestimación de la reclamación en la vía administrativa ${ }^{49}$. Si bien la posibilidad de interposición de la reclamación ante la autoridad independiente de control es potestativa conforme a lo previsto en el artículo 24 de esta norma. Es decir, el sistema de impugnación de las solicitudes de acceso fija una doble vía de control: la impugnación ante los tribunales contencioso administrativos conforme a los previsto en la Ley de la Jurisdicción contencioso administrativa o mediante la interposición de una reclamación ante la autoridad administrativa de control, el Valedor do Pobo como Comisiona-

48 Cfr. CARBALLO MARTÍNEZ, G.: La mediación administrativa y el Defensor del Pueblo, Thomson-Aranzadi, Cizur Menor, 2008, pp.261-262.

49 Sobre cuestiones específicas como son las particularidades las relativas a la tramitación del recurso judicial; a la competencia de los tribunales en los supuestos de reclamación judicial directa o tras la desestimación de la reclamación en vía administrativa; o la extensión de la posibilidad de conocimiento de los tribunales también el el supuesto de actos dictados por sujetos privados como fundaciones o sociedades debe consultarse BARRERO, C.: "El derecho de acceso a la información: publicidad pasiva", en en VV.AA. Transparencia, Acceso a la Información Pública y Buen Gobierno. Estudio de la Ley 19/2013, de 9 de diciembre, E. GUICHOT (Coord.), colección práctica jurídica, editorial Tecnos, Madrid, 2014, pp. 244-246. 
do de Transparencia conforme el artículo 28.1 de la Ley 1/2016. Al respecto, la disposición adicional quinta de la Ley gallega 1/2016 determina expresamente que le corresponde también al Valedor la resolución de la reclamación prevista en el artículo 24 de la Ley 19/2013, de 9 de diciembre, de transparencia, acceso a la información pública y buen gobierno, en el supuesto de resoluciones dictadas por las entidades locales de Galicia.

En todo caso, debemos añadir que tampoco se puede tampoco excluir la facultad general del Defensor del Pueblo sobre la Administración autonómica gallega por lo que resultan útil el empleo de instrumentos de colaboración también en este ámbito como hemos destacado en párrafos anteriores. Como apunta COLOMER VIADEL, la complejidad técnica y burocrática actual del Estado y de sus diferentes administraciones plantea la necesidad del fortalecimiento máximo de la institución no de forma aislada sino mediante una red simbiótica que integre a todas las defensorías con el fin de proteger con la mayor eficacia posible los derechos de los ciudadanos e impulsar su acción ante cualquier comportamiento irregular de las administraciones ${ }^{50}$. A lo largo de estos años la dinámica positiva de cooperación entre los Defensores - materializada mediante la suscripción de convenios o Jornadas anuales de cooperación - ha permitido que no se materializase el riesgo de que los órganos administrativos interpusiesen excepciones de competencia en sus actuaciones ${ }^{51}$ lo que redunda en una mayor garantía de los derechos de la ciudadanía. Por este motivo, el prestigio y el buen funcionamiento de un verdadero sistema político transparente de buen gobierno lejos de centrar la supervisión de las Administraciones Públicas

50 Cfr. COLOMER VIADEL, A.: "El Defensor del Pueblo: un órgano políticoadministrativo de protección de los derechos", Revista de Derecho Político, no 70-71, enero-agosto, UNED, Madrid, 2008, p.62 (http://e-spacio. uned.es/fez/eserv.php?pid=bibliuned:DerechoPolitico2008-2\&dsID=PDF página web consultada 25/09/2017 a las $16.54 \mathrm{~h}$ )

51 Cfr. COLOMER VIADEL, A.: El Defensor del Pueblo, Protector de los Derechos y Libertades y Supervisor de las Administraciones Públicas, Civitas Thonsom-Reuters, editorial Aranzadi, Cizur Menor, pp.151-152. 
en un único instrumento de control plantea la necesidad de que se articule de forma coordinada sobre diversos instrumentos jurídicos y políticos autónomos e independientes. Todo un abanico de posibilidades de defensa de las que dispone el administrado ante un funcionamiento irregular de las Administraciones públicas. El protagonismo otorgado en este ámbito al Valedor do Pobo, con los problemas y deficiencias destacados, por la Ley 1/2016 debe ser interpretado en este sentido.

\section{Conclusiones}

Cualquier reforma institucional que se proponga con el fin de disminuir la corrupción política y mejorar el funcionamiento de las instituciones públicas debe ir acompañada de un refuerzo de la imparcialidad y de la confianza ciudadana en la política y en los políticos. Una confianza social que requiere romper la idea de impunidad y reducir las oportunidades de corrupción. La forma más clara de entender la rendición de cuentas sería, aparentemente, identificarla como una malla de responsabilidades en el sentido de que el gobernante rindiese cuentas de sus actos de forma diversa - jurídica, política y moralmente - ante distintos sujetos - tribunales, el parlamento, el jefe del ejecutivo, el partido, los medios de comunicación, la opinión pública, el electorado, los grupos de presión, las agrupaciones locales de su partido, su propia circunscripción, algunas instancias internacionales, etc $-{ }^{52}$ mediante los más variados mecanismos entre los que se incluyen las defensorías del pueblo.

La Ley gallega 1/2016 se caracteriza por no sólo dar un paso más allá de lo previsto en la legislación autonómica previa, si no también por integrar en una única norma toda la regulación referida a la rendición de cuentas de los poderes públicos gallegos en el marco de la Ley estatal 19/2013. Es decir, la nue-

52 Cfr., BUSTOS GISBERT, Rafael: "Corrupción política: Un análisis desde la Teoría Jurídico-Constitucional", Revista Teoría y Realidad Constitucional, n²5, UNED, Madrid, 2010, p.103. 
va Ley de transparencia y buen gobierno regula tanto los datos derivados de la actividad administrativa y gubernamental autonómica como los mecanismos de control las buenas prácticas de aquellas personas que tienen responsabilidades públicas. Al convertir a la figura Alto comisionado del Parlamento gallego en un protagonista en este ámbito, se suscitan nuevos problemas. Aunque la función para la democratización que presenta esta institución puede ser decisiva por llegar donde no llegan las demás instituciones de control ${ }^{53}$, como reconoce FERNÁNDEZ RODRÍGUEZ, no puede pensarse en las defensorías como la panacea de los problemas del sector público ${ }^{54}$ ni tampoco, como hemos visto a lo largo de este estudio, como un instrumento plenamente eficaz. Nos encontramos ante una institución que se ha desenvuelto en un marco legal de mínimos lo que le ha permitido cierta flexibilidad de funcionamiento y ejercicio en el ámbito del control de la mala administración y de la mediación entre la Administración y el ciudadano ${ }^{55}$. Sin embargo, al otorgarle un nuevo protagonismo a las Defensorías como garantía

53 La labor de supervisión Defensor del Pueblo comprende no sólo constatación del incumplimiento del Derecho si no que, además, incluye la valoración crítica de las normas y la propuesta bien de reforma de las disposiciones normativas incompatibles con los derechos humanos o bien de otras nuevas destinadas a lograr una nueva efectividad ( $C f r$., ESCOBAR ROCA, G.: "Introducción a la teoría jurídica de los derechos humanos", Trama, Madrid, 2005, p.138, cit. por FERNÁNDEZ RODRÍGUEZ, J. J.: Defensorías del Pueblo en España: una visión prospectiva, Cuadernos de democracia y derechos humanos, ${ }^{\circ} 11$, Cátedra de derechos humanos y democracia, Universidad de Alcalá, Madrid, 2014, p.25).

54 Cfr. FERnÁndeZ RODRÍGUEZ, J. J.: Defensorías del Pueblo en España: una visión prospectiva, Cuadernos de democracia y derechos humanos, $\mathrm{n}^{\circ} 11$, Cátedra de derechos humanos y democracia, Universidad de Alcalá, Madrid, 2014, p. 24.

55 CARBALLO MARTÍNEZ con la expresión "marco legal de mínimos" subraya que el legislador ha optado por la regulación de la institución de una forma poco detallada con el fin de que su titular disfrutase de una mayor libertad mediadora lo que cosultancialmente relaciona con la falta de su poder coactivo. (Cfr. CARBALLO MARTÍNEZ, G.: La mediación administrativa y el Defensor del Pueblo, Thomson-Aranzadi, Cizur Menor, 2008, pp.209215). 
de la buena administración se plantea la necesidad de un avance. La garantía de su independencia, la débil fuerza coercitiva de sus resoluciones, la articulación del principio de colaboración, la determinación en cuanto al sujeto pasivo así como sobre el concepto de actividad administrativa susceptible de la labor fiscalizadora del Valedor pueden suponer un grave problema en el ejercicio de sus funciones de control si no se revierten de fuerza coercitiva.

La definición de marcos legales claros y precisos se convierte en una estrategia esencial de prevención de la corrupción pública con el fin de que no dejar ningún margen susceptible de interpretación ${ }^{56}$. Por este motivo, cualquier contorno impreciso o indeterminado del instrumento de supervisión se convierte en un punto débil que, en último caso, puede condicionar la eficacia de su actuación de control y prevención frente la corrupción. De este modo, urge una solución a los problemas de indeterminación y a los nuevos retos señalados. Asimismo es necesario la superación de ciertos problemas estructurales como el riesgo de instrumentalización político-partidista o grupos de interés político-económicos, su acercamiento a la ciudadanía a la promoción de buenas prácticas, la implementación de una verdadera administración electrónica - en la que se permita comprobar los datos del reclamante y las sanciones impuestas ante las mala praxis-, para que su actividad supervisora y de control de la transparencia y buenas prácticas de la administración sea eficiente.

En todo caso, como subraya GUICHOT, no podemos obviar que una ley de transparencia es un instrumento útil para la persecución de la corrupción y la mejora del Gobierno, pero requiere el establecimiento de mecanismo efectivos de aplicación y la existencia de una ciudadanía activa que ejerza el derecho

56 Cfr., VÁZQUEZ PORTOMEÑE SEIJAS, Fernando: "Corrupción política y globalización. Una mirada a la regulación del tráfico de influencias en los instrumentos internacionales anti-corrupción", en Revista Dereito: Revista xurídica da Facultade de Dereito, vol. 26, $\mathrm{n}^{\circ} 1$, enero-junio, USC, 2017, pp.2 y 3 (http://www.usc.es/revistas/index.php/dereito/article/download/3727/4484, página web consultada 1/9/2017 a las 09.00h). 
a saber para que nos hallemos ante un instrumento efectivo de lucha contra la corrupción política ${ }^{57}$. El hecho de que en España la transparencia se implementase de abajo a arriba, por demanda ciudadana ante los casos de corrupción política, ha planteado un resultado contrario al que se pretendía: la desconfianza ciudadana en la política y las instituciones. Una brecha que se ve incrementada por las posibles interpretaciones que se puedan producir en aplicación de la Ley. La acción de los operadores jurídicos, como el Valedor do Pobo, cobra un protagonismo absoluto ya que la transparencia será real si las autoridades de control están cualificados y actúan de una forma eficaz e independiente de hecho y derecho. Si no se consiguen solucionar los problemas descritos se corre un gran riesgo: la mera apariencia de unos cambios jurídico-político de las instituciones sin que se produzca una verdadera reforma lo que puede genera el efecto contrario. Un efecto Lampedusa que puede producir un incremento de la desconfianza y una quiebra del modelo político que conocemos.

\section{Referencias bibliográficas de consulta}

AA.VV.: Estudios sobre o Estatuto Galego, J. RODRÍGUEZARANA MÚÑOZ(coord.), Escola Galega de Admininistracoión Pública (EGAP), Santiago de Compostela, 1991.

AA.VV.: Comentarios al Estatuto de Autonomía de la Comunidad Autónoma de Galicia, J.L. CARRO FERNÁNDEZVALMAYOR (coord.), colección legislación y jurisprudencia, Ministerio para las Administraciones Públicas, Instituto Nacional de Administración Pública (INAP), Madrid, 1991.

57 Cfr. GUICHOT REINA, E.: "Reflexiones acerca de la nueva normativa sobre transparencia pública" en Administración de Andalucia: revista Andalus de administración pública, $\mathrm{n}^{\circ} 94$, Universidad de Sevilla- Instituto andaluz de la Administración Pública, Sevilla, 2016, pp.93-105. 
AA.VV.: Comentarios a la Constitución, Tercera edición ampliada, R. GARRIDO FALLA (dir.), Civitas Ediciones SL., Madrid, 2001.

AA.VV.: Comentarios a la Ley orgánica del Defensor del Pueblo, Antonio ROVIRA VIÑAS (dir.), colección Monografías Aranzadi, no 231, Defensor del Pueblo y Thomson, editorial Aranzadi, Cizur Menor, 2002.

AA.VV.: Régimen jurídico del Defensores del Pueblo, colección publicaciones, Defensor del Pueblo, Madrid, 2002.

AA.VV.: "Encuesta sobre el Defensor del Pueblo", en la Revista Teoría y Realidad Constitucional, n²6, UNED, Madrid, 2010, pp.15-73.

AA.VV.: Código de Transparencia y derecho de acceso a la información pública, José Miguel HERNÁNDEZ LÓPEZ (dir.), colección textos legales, $\mathrm{n}^{\circ} 231$, INAP, editorial Tirant lo Blanch, Valencia, 2015.

AGUIAR de LUQUE, L.: "Defensor del Pueblo", en AA.VV. Derechos fundamentales y su protección. Temas básicos de Derecho Constitucional. Tomo III, M. ARAGÓN REYES (dir.), Civitas Thonsom-Reuters, editorial Aranzadi, Cizur Menor, 2011, pp. 127-131.

de ANDRÉS ALONSO, F. L.: Los Defensores del Pueblo en España, colección filosofía y sociología jurídica, editorial Reus, Madrid, 2017.

BARRERO, C.: "El derecho de acceso a la información: publicidad pasiva", en en VV.AA. Transparencia, Acceso a la Información Pública y Buen Gobierno. Estudio de la Ley 19/2013, de 9 de diciembre, E. GUICHOT (Coord.), colección práctica jurídica, editorial Tecnos, Madrid, 2014, pp. 199-246.

BLANCO VALDÉS, R. L.: La Constitución de 1978, (Segunda edición), Alianza Editorial, Madrid, 2011.

BUSTOS GISBERT, Rafael: "Corrupción política: Un análisis desde la Teoría Jurídico-Constitucional”, Revista Teoría y Realidad Constitucional, n²5, UNED, Madrid, 2010, pp.69-109. 
CARBALLO MARTÍNEZ, G.: La mediación administrativa y el Defensor del Pueblo, Thomson-Aranzadi, Cizur Menor, 2008.

COLOMER VIADEL, A.: "El Defensor del Pueblo: un órgano políticoadministrativo de protección de los derechos", Revista de Derecho Político, $\mathrm{n}^{\circ} 70-71$, enero-agosto, UNED, Madrid, 2008, pp.59-83. (http://e-spacio.uned. es/fez/eserv.php?pid=bibliuned:DerechoPolitico2008$2 \& d s I D=P D F$ página web consultada $25 / 09 / 2017$ a las 16.54h).

COLOMER VIADEL, A.: "La independencia del Defensor del Pueblo frente a los partidos políticos", Revista Teoría y Realidad Constitucional, n²6, UNED, Madrid, 2010, pp.353-367. (https://dialnet.unirioja.es/descarga/articulo/3333194.pdf página web consultada el 26/09/2017 a las 20.53h).

COLOMER VIADEL, A.: El Defensor del Pueblo, Protector de los Derechos y Libertades y Supervisor de las Administraciones Públicas, Civitas Thonsom-Reuters, editorial Aranzadi, Cizur Menor, 2013.

CORA RODRÍGUEZ, J.: "O Valedor do Pobo" Estudios sobre o Estatuto Galego, J. RODRÍGUEZ-ARANA MÚÑOZ (coord.), Escola Galega de Admininistracoión Pública (EGAP), Santiago de Compostela, 1991, pp.339-349.

FERNÁNDEZ RODRÍGUEZ, J. J.: "Defensor del Pueblo y defensorías autonómicas: Reflexiones sobre sus relaciones y posición recíproca", Revista Teoría y Realidad Constitucional, n²6, UNED, Madrid, 2010, pp.259-283.

FERNÁNDEZ RODRÍGUEZ, J. J.: Defensorías del Pueblo en España: una visión prospectiva, Cuadernos de democracia y derechos humanos, $\mathrm{n}^{\circ} 11$, Cátedra de derechos humanos y democracia, Universidad de Alcalá, Madrid, 2014.

GARRIDO FALLA, R.: "Artículo 54", en AA.VV.: Comentarios a la Constitución, Tercera edición ampliada, R. GARRIDO FALLA (coord.), Civitas Ediciones SL., Madrid, 2001, pp.989-998. 
GUICHOT REINA, E.: "El Consejo de Transparencia y Buen Gobierno" en VV.AA. Transparencia, Acceso a la Información Pública y Buen Gobierno. Estudio de la Ley 19/2013, de 9 de diciembre, E. GUICHOT (Coord.), colección práctica jurídica, editorial Tecnos, Madrid, 2014, pp.331-351.

GUICHOT REINA, E.: "Reflexiones acerca de la nueva normativa sobre transparencia pública" en Administración de Andalucía: revista Andalus de administración pública, $\mathrm{n}^{\circ} 94$, Universidad de Sevilla-Instituto andaluz de la Administración Pública, Sevilla, 2016, pp.89-106.

MAIZ SUÁREZ, R.: “Artículo 14” en Comentarios al Estatuto de Autonomía de la Comunidad Autónoma de Galicia, J.L. CARRO FERNÁNDEZ-VALMAYOR (coord.), colección legislación y jurisprudencia, Ministerio para las Administraciones Públicas, Instituto Nacional de Administración Pública (INAP), Madrid, 1991, pp.169-177.

PÉREZ ROYO, J.: Curso de Derecho Constitucional, (Decimocuarta edición), Marcial Pons, Madrid, 2014.

TORRES MURO, I.: "Los recursos del Defensor del Pueblo ante el Tribunal Constitucional. Una revisión", en la Revista Teoría y Realidad Constitucional, n²6, UNED, Madrid, 2010, pp.95-125.

VARELA SUANZES-CARPEGNA, J.: "Naturaleza jurídica del Defensor del Pueblo", Revista Española de Derecho Constitucional, Año 3, $\mathrm{n}^{\circ} 8$, mayo-agosto, 1983, pp. 63-80. (https://dialnet.unirioja.es/descarga/articulo/249714.pdf, página web consultada 27/06/2017 a las 16.54h).

VÁZQUEZ-PORTOMEÑE SEIJAS, F.: "Sobre el bien jurídico protegido por el delito de obstaculización a las actuaciones del Defensor del Pueblo (Art. 502.2 CP)", Revista Electrónica de Ciencia Penal y Criminología (RECPC), $\mathrm{n}^{\mathrm{o}} 14-15,2012$, p. 15:1-15:19. (http://criminet. ugr.es/recpc/14/recpc14-15.pdf, página web consultada $17 / 07 / 2017$ a las $09.40 \mathrm{~h})$. 
VÁZQUEZ PORTOMEÑE SEIJAS, F.: “Corrupción política y globalización. Una mirada a la regulación del tráfico de influencias en los instrumentos internacionales anticorrupción", en Revista Dereito: Revista xurídica da Facultade de Dereito, vol. 26, nº 1 , enero-junio, USC, 2017, pp. 1-25 (http://www.usc.es/revistas/index.php/dereito/ article/download/3727/4484, página web consultada 1/9/2017 a las 09.00h).

VERA SANTOS, J. M.: El Defensor del Pueblo en la Constitución y en los Estatutos de autonomía, colección textos y documentos, $\mathrm{n}^{\mathrm{o}} 13$, Centro de Estudios Político Constitucionales, BOE, Madrid, 2002. 